\title{
Series documentales para el estudio del poder en las Universidades Hispánicas de los ss. XVI-XVIII: El caso salmantino
}

\author{
Agustín Vivas Moreno \\ Universidad de Extremadura - UEx, España
}

REVIEW

\begin{abstract}
Resumen
Objetivo.. Identificar y analizar las series documentales conservadas en los archivos históricos universitarios que son de utilidad para el estudio del poder universitario durante los siglos XVI-XVIII. Para ello nos centraremos en el estudio de la más importante de las universidades clásicas: la Universidad de Salamanca.

Método. Seguiremos la metodología institucional, según la cual, en primer lugar estudiaremos la institución productora de la documentación, para posteriormente analizar la documentación generada e identificar las series objeto de estudio.

Resultados. Tras el análisis de las diferentes procedencias y series documentales generadas, concluiremos que el análisis del poder universitario refiere documentación procedente del Archivo Histórico Antiguo (documentos fundacionales, Constituciones, privilegios y bulas pontificias; Estatutos, provisiones, cédulas y privilegios reales, etc.) de la Secretaría del Estudio (esencialmente lo concerniente al gobierno interno con especial mención a las series emanadas de los claustros académicos), del Maestrecuela y Audiencia Escolástica y de las múltiples y variadas procedencias de las instituciones vinculadas -esencialmente colegiales-, que, naturalmente, generan una documentación para el estudio de sus estructuras de gobierno y poder

Conclusiones. Las conclusiones pueden ser transferidas a gran parte de las universidades peninsulares e iberoamericanas, que siguen en gran medida el mismo modelo fundacional y estatutario que la Salamantina.
\end{abstract}

Palabras clave

Archivos universitarios; Poder; Series documentales; Universidad de Salamanca.

Documentary series for the study of power in the Hispanic Universities of the $16^{\text {th }}-18^{\text {th }}$ centuries: The Salamanca case

\section{Abstract}

Objective: Identify and analyze the documentary series preserve in the archive of historical manuscripts at the university that are used for the study of the power of the universities along the centuries XVI-XVII. For this, we will focus on the University of Salamanca.

Method: Firstly, we will study the institution that do the documentation for later, identify and analyze the series that are under study.

Results: We can found documentation at the archive of historical manuscripts, in the secretary, in the scholastic audience and many more institutions.

Conclusions: The implementation to so many peninsular and Ibero- American universities that follow the same model that Salamanca University.

Keywords

Documentary series; Power; University archives; University of Salamanca. 


\section{Introducción}

La Universidad no es hoy ni ha sido nunca un espacio pertinaz y aséptico de conocimiento, sino una institución más que debe ser enmarcada en su contexto histórico y en sus conexiones con el poder ${ }^{1}$. Dicha vinculación se argumenta en dos líneas: por un lado, en el mantenimiento de los equilibrios institucionales internos que justifican las diferentes y cambiantes estructuras gubernativas universitarias, y por otro, en las relaciones con las instituciones suprauniversitarias, monárquicas y pontificias fundamentalmente, que inciden directamente en la jurisdicción docente y estudiantil. Por su parte, los archivos universitarios reflejan el devenir de la institución que les cobija, instituciones que han tenido una enorme importancia en la historia de la Monarquía Hispánica, dado que por sus aulas pasaron gran parte de las personas que ocuparon puestos de poder tanto en la administración civil como eclesiástica.

El objetivo fundamental que nos proponemos con esta investigación es identificar y analizar las series documentales conservadas en los archivos históricos universitarios que son de utilidad para el estudio del poder universitario durante los siglos XVI-XVIII, esto es, durante los siglos más relevantes de la Monarquía Hispánica. Para ello, seguiremos una metodología institucional, según la cual, en primer lugar es necesario el estudio de la institución productora de la documentación, para posteriormente analizar la documentación generada e identificar las series objeto de estudio.

Nos centraremos para ello en la Universidad de Salamanca, una de las grandes universidades europeas y, seguramente, la más importante de las Universidades clásicas españolas. Sus aulas fueron referente de ciencias jurídicas y teológicas, sus matriculados ocuparon cuantiosos puestos de poder, y su historia, verdadera imagen representativa de una etapa determinada de la Monarquía Hispánica. Al hilo, sus estructuras gubernativas y los resortes para el estudio del poder fueron exportados, como veremos, a través de sus Constituciones y Estatutos a otras muchas universidades peninsulares y americana, por lo que podemos afirmar que los resultados aquí expuestos para la Salmantina pueden ser extrapolables a otras universidades del contexto.

Dicho esto, tal y como es sabido, la universidad salmantina es la que mayor número de estudios y publicaciones históricas ha provocado. Además, el período moderno de los ss. XV-XVIII, época en que la Salmantina se convierte en universidad modelo, la que ha recibido un tratamiento destacadamente prioritario. El poder, ciertamente, no ha sido una de las áreas más sistemáticamente tratadas, si bien en las últimas tres décadas se ha logrado un desarrollo acelerado. Respecto a las distintas Constituciones y Estatutos universitarios contamos con las contribuciones de Francisco Javier Alejo Montes, Pilar Valero, González de la Calle, Huarte y Echenique, José Luis Fuertes, Fernández Álvarez, y Rodríguez-San Pedro entre otros. ${ }^{2}$ Sin embargo, salvo algunas

\footnotetext{
1 Fundamental: RODRíGUEZ-SAN PEDRO BEZARES, L.E. (coord.). Historia de la Universidad de Salamanca. Vol. I: Trayectoria histórica e instituciones vinculadas, Salamanca, Ediciones Universidad de Salamanca, 2002, 752 pp. (Colección: "Historia de la Universidad", n. ${ }^{0}$ 61); RODRíGUEZ-SAN PEDRO BEZARES, L.E. (coord.), (coord.), Historia de la Universidad de Salamanca. Vol. II: Estructuras y flujos, Salamanca, Ediciones Universidad de Salamanca, 2004, 986 pp. (Colección: "Historia de la Universidad", RODRíGUEZ-SAN PEDRO BEZARES, L.E. (coord.). Historia de la Universidad de Salamanca. Vols. III.1-2: Saberes y confluencias, Salamanca, Ediciones Universidad de Salamanca, 2006, 1.418 pp. (Colección: "Historia de la Universidad", n. ${ }^{\circ}$ 63); RODRÍGUEZ-SAN PEDRO BEZARES, L.E. y POLO RODRÍGUEZ, J.L. (coords.), Historia de la Universidad de Salamanca. Vol. IV: Vestigios y entramados, Salamanca, Ediciones Universidad de Salamanca, 2009, 860 pp. (Colección: "Historia de la Universidad", n. ${ }^{\circ}$ 64).
}

RODRÍGUEZ-SAN PEDRO BEZARES, L.E. y POLO RODRÍGUEZ, J.L. (eds.), Fuentes archivos y bibliotecas para una historia de las Universidades Hispánicas. Miscelánea Alfonso IX, 2014, Salamanca, Ediciones Universidad de Salamanca, 2015, 432 pp. (Colección "Aquilafuente", 211).

2 ALEJO MONTES, F.J. La reforma de la Universidad de Salamanca a finales del s. XVI: Los Estatutos de 1594. Salamanca, 1990; VALERO GARCíA, P. "Un aspecto del rectorado de Fernán Pérez de Oliva: pretendidos Estatutos de la Universidad de Salamanca bajo su mandato" en Stvdia Histórica. Historia Moderna. Salamanca, 1986, vol. IV, pp. 51-74;; GONZÁLEZ DE LA CALLE, P.U. y HUARTE Y ECHENIQUE, A. "Constituciones de la Universidad de Salamanca. 1422. Edición paleográfica. Con prólogo y notas" en Revista de Archivos, Bibliotecas y Museos. Madrid, 1925-26, n 46, pp. 217-228, 345-359, y 402-419; no 47, pp. 348-371, y 467-501; FUERTES, J.L. Estatutos de la Universidad de Salamanca, 1529. Mandato de Pérez de Oliva, Rector. Salamanca, 1984; FERNÁNDEZ ÁlVAREZ, M. "La reforma universitaria de 1512" en Stvdia Histórica. Historia Moderna. Salamanca, 1984, vol. II, n³, pp. 21-46; RODRÍGUEZ-SAN PEDRO BEZARES, L.E. Estatvtos 
honrosas excepciones, no se establecen análisis comparativos que pueden sernos de cierta utilidad (Rodríguez Cruz, Rodríguez-San Pedro Bezares). ${ }^{3}$

Por otro lado, son limitadas las monografías sobre asuntos y cargos de relevancia. Contamos, en este sentido, con algunas de fuerte consolidación vinculadas al privilegio jurisdiccional y su compleja evolución en el estudio salmantino, el oficio de rector y sus cualidades, o el del Maestrescuela y su participación en el gobierno universitario, ligadas a nombres como M $\mathrm{M}^{\mathrm{a}} \mathrm{P}$. Alonso Romero, Águeda Rodríguez Cruz, Juan Luis Polo Rodríguez o Daniel Sánchez y Sánchez. ${ }^{4}$ Igualmente, aunque más lejanas en el tiempo, son algunas de las obras de Antonio García Boiza y Beltrán de Heredia sobre algunos asuntos de matices más concretos. Así, el primero estudia la intervención de los estudiantes en el poder universitario, y el segundo se ocupa de la Cancillería medieval y su continuación renacentista. ${ }^{5}$

Asimismo, formando parte de obras más generales, encontramos algunas panorámicas sobre los diversos mecanismos de poder, análisis de determinados organismos que forman parte del entramado institucional, diputados y niveles de representatividad, etc. (Rodríguez Cruz, Rodríguez-San Pedro Bezares, Valero García, Polo Rodríguez, Marcos de Dios, etc.). ${ }^{6}$ Mención aparte merecen los trabajos sobre la posibilidad de reformas institucionales, venidos de la mano de Manuel Fernández Álvarez, María Fernández Ugarte, Ma P. Alonso, Alejo Montes, Polo Rodríguez, Mariano Peset y José Luis Peset. ${ }^{7}$ Asimismo, disponemos de algunas contribuciones

hechos por la Universidad de Salamanca (1625), estudio y edición al cuidado... edición facsímil. Salamanca: Universidad de Salamanca, 1990.

${ }^{3}$ Estudios comparativos: RODRÍGUEZ CRUZ, Á. "Análisis comparativo de las constituciones universitarias de Salamanca con las hispanoamericanas" en Estudios de Historia Social y Económica de América (EHSEA), 1996, 13, pp. 583591. Quizás la contribución de RODRÍGUEZ-SAN PEDRO BEZARES, L.E. "Evolución del corpus legislativo en la Universidad de Salamanca (ss. XV-XVIII). Estado de la Cuestión" en Estudios de Historia Social y Económica de América (E.H.S.E.A.), 1996, 13, pp. 573-582; y una versión corregida y remodelada "Poderes y corpus normativo en la Universidad de Salamanca (Siglos XV-XVIII)" en Cuadernos del Instituto Antonio de Nebrija de estudios sobre la Universidad, 1998, 1, pp. 289-308.

${ }^{4}$ ALONSO ROMERO, Ma P. Universidad y sociedad corporativa: Historia del privilegio jurisdiccional del Estudio salmantino. Madrid. Tecnos, 1997; RODRÍGUEZ CRUZ, A. El oficio de Rector en la Universidad de Salamanca y en las Universidades Hispanoamericanas. Desde sus orígenes hasta principios del siglo XIX. Salamanca, 1979; e ídem. "El nivel institucional 2. Autoridades académicas, siglos XV-XVIII" en Universidad de Salamanca. Salamanca: Universidad de Salamanca, 1990, pp. 355-398; POLO RODRíGUEZ, J.L. "La autoridad rectoral y sus consejeros en la Universidad de Salamanca: 1700-1759" en Salamanca. Revista Provincial de Estudios. Salamanca, 1992. № 29-30, pp. 129-200; idem. "Veintinueve apercibimientos del Juez del Estudio de la Universidad de Salamanca (1736-1759)" en Espacio, Tiempo y Forma. Historia Moderna, 1994, IV, t. 7, pp. 143-167; ídem. "Poderes representativos en la Universidad de Salamanca del siglo XVIII: rector y consiliarios". En: Historia y Universidad. Homenaje a Lorenzo Mario Luna. México: UNAM, 1996, pp. 481-517; SÁNCHEZ y SÁNCHEZ, D. "El oficio de maestrescuela en la Universidad de Salamanca. Luces y sombras en el ejercicio del cargo en el siglo XVI". En: Salamanca y su proyección en el mundo. Homenaje a don Florencio Marcos Rodríguez. Salamanca: Ortega, 1992 pp. 61-80.

${ }^{5}$ GARCíA BOIZA, A. La intervención de los estudiantes en la Universidad de Salamanca en el s. XVI. Salamanca, 1933; BELTRÁN DE HEREDIA, V. La Cancillería de la Universidad de Salamanca. Salamanca, 1954.

${ }^{6}$ Vid. una síntesis en RODRÍGUEZ CRUZ, A. Historia de la Universidad de Salamanca. Madrid: Fundación ramón Areces, 1990. RODRíGUEZ-SAN PEDRO BEZARES, L.E. "Representatividad social de los Consiliarios". En: La Universidad salmantina... Op. Cit., vol. I, p. 366-377; VALERO, P. "El nivel institucional. Gobierno estatutario" En: La Universidad de Salamanca... Op. Cit., vol. II, pp. 325-353, POLO RODRÍGUEZ, J.L. "Poderes representativos en la Universidad de Salamanca del siglo XVIII: rector y consiliarios". En: GONZÁLEZ, E. (Ed.) Historia y Universidad. Homenaje a Mario Lorenzo Luna. México: UNAM, 1996, pp. 481-517; MARCOS de DIOS, Á. "Los consiliarios ex regno Portugaliae en la Universidad de Salamanca". En: Homenaxe á profesora Pilar Vázquez Cuesta. Santiago de Compostela: Universidad, 196, pp. 745-761, etc.

${ }^{7}$ FERNÁNDEZ ÁLVAREZ, M. "La reforma universitaria [de 1512]" en Stvdia Historica. Historia Moderna, 1984, II, 3 , pp. 21-46; FERNÁNDEZ UGARTE, Ma " "Estatutos de la Universidad de Salamanca: la Reforma de 1550-1551" en Stvdia Historica. Historia Moderna, 1989, II, pp. 687-705; ALONSO ROMERO, Mª P. "Sobre la jurisdicción y el gobierno de la Universidad de Salamanca a fines del siglo XVI" en Stvdia Historica. Historia Moderna, 1993, XI, pp. 117-147; ALEJO MONTES, F.J. "La reforma educativa de Juan de Zúñiga en la Universidad de Salamanca" en Historia de la Educación. Revista Interuniversitaria, 1990, 9, pp. 183-196; ídem. La reforma de la Universidad de Salamanca a finales del s. XVI. LoS Estatutos de 1594. Salamanca, 1994; RODRíGUEZ-SAN PEDRO BEZARES, L.E. La Universidad Salmantina del Barroco. Salamanca: Caja de Ahorros y Monte de Piedad de Salamanca, 1986, 3 vols., pp. 305-340 (trata de las reformas de 1602, 1610 y 1618); POLO RODRÍGUEZ, J.L. "Reformas en la Universidad de Salamanca de los primeros Borbones (1700-1759)" 
que analizan las relaciones entre la institución salmantina y el Estado (Carabias Torres, C. Möller, etc.) ${ }^{8}$, la pedagogía del poder en la universidad salmantina en momentos determinados (como ejemplo, los claustros en la época de Carlos V por C. Möller, o la jurisdicción y el gobierno de la Universidad a fines del s. XVI por Alonso Romero, etc ${ }^{9}$ ) o las interesantes contribuciones de M. Peset sobre modelos y estatutos de las universidades hispanas y sus equilibrios de poderes. ${ }^{10}$

Carecemos, sin embargo, de estudios monográficos y exhaustivos que analicen las relaciones de poder con el Papado y con la Monarquía ${ }^{11}$. Desde otra perspectiva, son igualmente insuficientes los análisis sobre el poder estudiantil y su vertebración, o los estudios funcionales y sociológicos de los oficiales universitarios, de tanta consideración para la comprensión de la generación y custodia de nuestra documentación (bedeles, administradores, mayordomos, etc.).

En conclusión, disponemos de no pocos estudios sectoriales, la curva de producción por años es alcista pero dispersa, originándose un panorama desigual y fragmentario. Asimismo, los resultados se caracterizan por las ausencias de estudios comparativos, grandes monografías y síntesis colectivas.

\section{Poderes e institución universitaria salmantina}

Veamos a continuación siquiera de forma muy esquemática, y con objeto de comprender posteriormente la documentación vinculada, cuál ha sido la distribución de poderes y cuál la disposición de competencias que acaban determinando la estructura del poder universitario a lo largo de los ss. XVI-XVIII.

La organización institucional de la Salamanca medieval quedó consolidada a través de normativas ratificadas por los Pontífices. Aparecen así las Constituciones de Benedicto XIII en 1381 y 1411 y las de Martín V en 1422, las cuales terminaron consolidándose como la carta magna de la Universidad, siguiendo rigiendo en sus títulos básicos hasta las reformas ilustradas y liberales de los siglos XVIII y XIX. ${ }^{12}$ Por lo que respecta a la distribución de poderes se constata una evolución que se desliza desde una amplia participación estudiantil en el gobierno del Estudio en sus comienzos, siguiéndose así el modelo boloñés, a una mayor participación de los docentes en los órganos decisivos, tales como claustros de diputados y plenos, de influencias nórdicas y parisinas. El cuadro

en Espacio, Tiempo y Forma, Serie IV. Historia Moderna, 1994, 7, pp. 145-174; PESET, M. y PESET, J.L. "Poder y reformas de la Universidad de Salamanca en tiempos de Carlos III". En: GONZÁLEZ, E. (Ed.) Historia y Universidad. Homenaje a Mario Lorenzo Luna. México: UNAM, 1996, pp. 457-480; ídem. El reformismo de Carlos III y la Universidad de Salamanca. Plan general de estudios. Salamanca, 1969.

${ }^{8}$ Entre otros: CARABIAS TORRES, A. Ma. "Notas sobre las relaciones entre el Estado y la Universidad en la España Moderna" en Stvdia Historica. Historia Moderna, 1989, VII, pp. 707-721; MÖLLER, C. La Universidad de Salamanca en la Monarquía de Carlos V. Lo hombres de letras como constructores de entornos de contrapoder. Tesis de Maestría, Mar de Plata, 1998.

${ }^{9}$ MÖLLER, C. La pedagogía del poder. Actitudes revolucionarias en los claustros salmantinos en la época de la Monarquía de Carlos V. Tesis doctoral leída en la Facultad de Educación de la Universidad de Salamanca, en septiembre de 1994, inédita; ALONSO ROMERO, Mª P. "Sobre la jurisdicción y el gobierno de la Universidad ... Op. Cit., pp. 117-147, etc.

${ }^{10}$ Entre otros trabajos: PESET, M. "Modelos y estatutos de las universidades españolas y portuguesas (siglos XIIIXVIII)". En: Dall'Università degli studenti all'Università degli studi, a cura di Andrea Romano, Messina: Presso l'Academia di Scienze Giuridiche, 1991, pp. 65-105; ídem. "La organización de las universidades españolas en la edad moderna". En: ROMANO, A. (Ed.) Studi e diretto nell'area mediterranea in età moderna. Materiali per una storia delle istituzioni giuridiche e politiche medievali, moderne e contemporanee. Messina: Rubettino, 1993, pp. 73-122.

${ }^{11}$ Algunos: CEPEDA BECERRA, J.P. El ejercicio del poder real en la Universidad de Salamanca 1556-1598. Grado de Salamanca presentado en la Facultad de Geografía e Historia de la Universidad de Salamanca, junio de 1997, inédito; VALERO, P. "Servicios del Estudio salmantino a la Corona". En: Actas del I Congreso de Historia de Salamanca... Op. Cit., pp. 293-303; GARCÍA ORO, J.; PORTELA SILVA, Ma J. Felipe II y la Universidad de Salamanca: Las Visitas del Consejo Real... Op. Cit.; idem. "Felipe II y la Universidad de Salamanca. Las visitas del Consejo Real" en Liceo Franciscano. Revista de Estudio e Investigación, 1998, 50, 151-153, pp. 273-422.

12 Cfr. GONZÁLEZ DE LA CALLE, P.U. y HUARTE Y ECHENIQUE, A. Constitutiones Universitati Studiorum Salamantinae datae a Pontifice Maximo Benedicto XIII die septimo ante kalendas sextiles anno millesimo quadrigentessimo undecimo. Zaragoza, 1932; BELTRÁN DE HEREDIA, V. Bulario de la Universidad de Salamanca (1218-1549). Salamanca, 4 vols. 1967-68, vol. 1, n 44; Constituciones de la Universidad de Salamanca (1422). Edición paleográfica, con prólogo y notas de Pedro Urbano González de la Calle y Amalio Huarte y Echenique. Madrid, 1927. 
de autoridades $y$ de oficiales que había en la Universidad de Salamanca en el s. XV, en los que no nos detendremos, era el siguiente: ${ }^{13}$ rector, diputados o definidores, maestrescuela o canciller, administrador, primicerio, síndico, conservadores, bedel, estacionario, tasadores, contadores, maestro de ceremonias y capellanes. Por su parte, los Claustros, que eran órganos colegiales de gobierno, podían ser de cinco tipos según los integrantes:

- Claustro pleno: también denominado Claustro de rector, catedráticos, diputados y consiliarios. Es la asamblea máxima, y sólo se reunía para asuntos extraordinarios tales como Constituciones, Estatutos, negociaciones con el rey o con el Papa.

- Claustro de rector, consiliarios y catedráticos: Se reunía para dar autorización de ausencias, provisión de sustituciones de los jubilados, etc.

- Claustro de rector y consiliarios: Encargado de elegir al rector, consiliarios, tasadores, síndico, bedel y estacionario. Tenía abundantes cometidos, entre las que destaca, quizás, lo concerniente a la provisión de cátedras.

- Claustro de diputados: se diseñó para conseguir un cierto equilibrio de poderes. Estaba formado por el rector, el maestrescuela y veinte diputados. Diez de sus miembros eran catedráticos ordinarios de propiedad, y otros diez pertenecían al profesorado auxiliar y a los graduados o simples estudiantes. Su poder estriba fundamentalmente en el control del arca de la Universidad y todo lo que ello comporta (préstamos, rentas, etc.).

- Claustro de catedráticos: integrado por los profesores de cátedras asalariadas y presidido por el primicerio. No asistía el rector, ya que era un estudiante. Se llama con frecuencia Claustro de primicerio y catedráticos.

En conclusión, a finales del s. XV encontramos un equilibrio proporcionado de poderes entre el sector docente y el discente.

Durante el reinado de los Reyes Católicos el gobierno universitario salmantino -que se había puesto del lado de los vencedores durante la Guerra de Sucesión- gozó del apoyo de la Corona. El control regio se estableció esencialmente a través de los denominados visitadores que intervinieron con rotundidad en algunos momentos de dificultad institucional motivado por la reiterada vulneración de las Constituciones. Al mismo tiempo, se advierte un mayor poder del Maestrescuela ${ }^{14}$, la otra gran jerarquía de la Universidad, máxima autoridad de la Audiencia Escolástica. Por otra parte, el gobierno seguía siendo compartido básicamente por los Claustros de Consiliarios, de Diputados y Pleno. Más adelante, en época de Carlos $V$ el gobierno institucional marcha hacia una mayor intervención estatal, con cierta decadencia del poder Papal. Asimismo, se constata una pérdida de representatividad y poder del Claustro de Consiliarios en pro de los Claustros Pleno y de Diputados. Todo ello originó la reforma universitaria carolina, cristalizada en los Estatutos de 1538 caracterizados por una mayor independencia del rector frente a los estamentos colegiados, una defensa frente a los nuevos poderes colegiales, y pequeñas novedades en relación con los claustros como forma de contrarrestar el poder del rector. ${ }^{15}$

Todo parece indicar que en época de Felipe II son los Claustros de Diputados y Pleno los órganos colegiales que regulan las más importantes decisiones institucionales. Característica de relieve para esta etapa son los múltiples Estatutos de 1560, revisionados en 1561 y reelaborados en 1594. De ellos, destaca, sin duda, los que impuso a la Universidad su visitador Diego de Covarrubias en 1561. Sus fines eran reglamentar más adecuadamente la vida universitaria, un estricto control de la enseñanza para evitar deslizamientos heréticos, y

13 Seguimos a los profesores Antonio García García ("Consolidaciones del s. XV" En: La Universidad de Salamanca...Op. Cit., I, pp. 37-42) y Águeda Rodríguez Cruz. ("El nivel institucional. 2. Autoridades Académicas..." Op. Cit., II, pp. 358-398).

${ }^{14}$ Cfr. ALONSO ROMERO, Ma. P. Universidad y sociedad corporativa. Historia del privilegio jurisdiccional del Estudio salmantino. Madrid: Tecnos, 1997 y FERNÁNDEZ ÁLVAREZ, M. "Etapa renacentista (1475-1598)" La Universidad de Salamanca... Op. Cit., p. 65.

${ }^{15}$ Cfr. FERNÁNDEZ UGARTE, Ma "Estatutos de la Universidad de Salamanca: la reforma de 1550-1551" en Stvdia Historica. Historia Moderna. Homenaje al Prof.. Fernández Álvarez. Salamanca, 1989. Vol. VII, pp. 687-705. 
una consolidación de la Monarquía autoritaria en la Universidad. ${ }^{16}$ En conclusión, características de esta época pudieran ser: una mayor intervención de la Corona en los asuntos de gobierno en forma de visitadores periódicos y establecimiento de Estatutos, y una cierta debilidad de las resoluciones pontificias. En definitiva, en el juego de los equilibrios de poder, hay una claro decantamiento en favor de la Corona y su Consejo de Castilla en perjuicio de las iniciativas papales. Al mismo tiempo, el rector debía seguir siendo estudiante, aunque restringido a los "generosos y nobles", el maestrescuela seguía gozando de la representatividad papal, y los claustros pleno y de diputados se configuraron como órganos clave de decisión.

Durante el s. XVII continúa modelo boloñés donde el estudiante, a pesar de perder algunos resortes e influencias, sigue participando directamente en los órganos de gobierno. En lo concerniente a la distribución de poderes se constata un retroceso del poder papal en beneficio de la Corona. Será ésta, fundamentalmente a través de sus visitadores, la encargada de la aprobación de los nuevos Estatutos, tal y como sucedió con Caldas en 1604, Gilimón de la Mota en 1610, y definitivamente con la Recopilación de $1625 .{ }^{17}$ Por su parte, la relación de estructuras de atribuciones y competencias se caracteriza por lo que Rodríguez-San Pedro, siguiendo a L. Stone, ha denominado como "aristocratización de los poderes" determinada por "una pérdida de protagonismo del alumnado, una concentración de poderes en los catedráticos de propiedad, y una mayor preeminencia de las oligarquías colegiales". ${ }^{18}$ Prueba de ello fueron las tentativas por parte de la Corona de que fueran los catedráticos de propiedad los que eligieran a los consiliarios, y que, asimismo, la elección del rector la estableciera el Consejo de Castilla de una terna propuesta. ${ }^{19}$ Al mismo tiempo, la representatividad de los catedráticos de propiedad en el cuerpo de diputados aumentó considerablemente a partir de 1618. En el resto de los órganos colegiales y oficios universitarios se constata la evolución que venimos describiendo: los claustros $u$ órganos colegiales de gobierno pierden autonomía en beneficio de las denominadas Juntas que, acrecentadas con el paso del tiempo, ganan en poder de decisión, y al mismo tiempo, la elección del maestrescuela queda vinculada a la corona, en perjuicio del claustro pleno.

Por su parte, en el s. XVIII se distinguen dos etapas: una primera, que podríamos denominar de continuista, con claras características tradicionalistas, donde el incipiente reformismo fue, a todas luces, insuficiente, y una segunda, fundamentalmente constatada desde el Plan de 1771, que podríamos titular de reformista, caracterizada por un aumento de poder por parte del monarca y su Consejo Real, mayores atribuciones del rector -ya preservado para graduados mayores-, seguido de un debilitamiento del poder del maestrescuela y de su jurisdicción. En definitiva, el siglo XVII y gran parte del s. XVIII conformarían un mismo período histórico universitario, dado que las características esenciales de la institución permanecen. ${ }^{20}$

El siglo comenzó con la Guerra de Sucesión, y la institución salmantina apostó por otorgar su fidelidad y apoyo "espiritual" $y$ "temporal" al Rey Felipe V. ${ }^{21}$ Juan Luis Polo analiza las contribuciones monetarias y otras donaciones en especie que la Universidad realiza al que fuera el bando vencedor y las consecuencias negativas

${ }^{16}$ Así los define Fernández Álvarez (Ibídem, pp. 86-87). Son indispensables, como decimos, las obras de Daniel Sánchez hasta 1575, y las de Alejo Montes para analizar los cambios estatutarios de 1594. (Vid. entre otras SÁNCHEZ SÁNCHEZ, D. La Universidad de Salamanca a través de sus claustros. Estructura jerárquica y académica (1555-1575). Tesis doctoral inédita. Salamanca, 1980; y ALEJO MONTES, F.J. La reforma de la Universidad de Salamanca a finales del siglo XVI: Los Estatutos de 1594. Salamanca: Universidad, 1990; y La Universidad de Salamanca bajo Felipe II (1575-1598). Valladolid: Junta de Castilla y León, 1998.

17 Constitutiones Apostólicas y Estatutos hechos por la muy insigne Vniversidad de Salamanca. Recopilados nuevamente por su comisión. Salamanca: Diego Cossío, 1625. Además hubo otras dos visitas: la de Ribera Báñez en 1653 y la de Matías Rada en 1667-1669, pero sus reformas no fueron ratificadas por el Consejo de Castilla. (Cfr. RODRíGUEZ-SAN PEDRO BEZARES, L.E. "Barroco y tradicionalismo..." Op. Cit., p. 104).

${ }^{18}$ RODRÍGUEZ-SAN PEDRO BEZARES, L.E. “La Universidad de Salamanca: Evolución...” Op. Cit., p. 14.

${ }^{19}$ Cfr. RODRÍGUEZ-SAN PEDRO BEZARES, L.E. "Barroco y tradicionalismo..." Op Cit., pp. 105-106.

${ }^{20}$ La expresión "reformismo insuficiente" es utilizada por Juan Luis Polo para definir la primera mitad de siglo. (Cfr. POLO RODRíGueZ, J.L. La Universidad del Antiguo Régimen..., pp. 592-595). La conclusión es de su aturía. (Cfr. "Reformas en la Universidad de Salamanca de los primeros Borbones (1700-1759)" en Espacio, Tiempo y Forma. Serie IV, Historia Moderna, t. 7, 1994, pp. 145-173; “La Universidad salmantina del setecientos”. En: Las Universidades Hispánicas: de la Monarquía de los Austrias al Centralismo Liberal. Valladolid: Junta de Castilla y León, 1996, 2 vols.

${ }^{21}$ Algunas noticias en VILLAR Y MACÍAS, M. Historia de Salamanca. Salamanca, 1887, 3 vols. (Reimp. 19731975, 9 vols.), libro VIII, cap. I, p. 8 y libro VIII, cap. II, pp. 27-30, etc.; e ídem. Memoria histórica de la Universidad de Salamanca. Salamanca, 1869, pp. 150-154. (Cfr. POLO RODRÍGUEZ, J.L. "Salamanca en la Guerra de Sucesión". En: Actas de I Congreso de Historia de Salamanca. Op. Cit., p. 249; e ídem. "La Universidad de Salamanca en la Guerra de Sucesión”. En: La Universidad salmantina del Antiguo Régimen (1700-1750) Op. Cit., pp. 221-234). 
para las finanzas (acumulación de deudas) y la docencia universitaria (ausencia de catedráticos). Sin embargo, el que nuestra institución se pusiera del lado del vencedor fue un verdadero acierto, si bien durante estos momentos no hubo ningún atisbo reseñable de reformas institucionales. ${ }^{22}$

En tiempos de Felipe $V$ y Fernando $V I$ hay dos intentos de reforma impulsadas por el estadista del regalismo Melchor de Macanaz, si bien la distribución de poderes, sus atribuciones y competencias no sufrieron importantes modificaciones. Dichas pretensiones, en su afán por renovar la formación educativa, propusieron la intensificación del Derecho Real en la enseñanza universitaria y la reducción de los encumbrados poderes colegiales. ${ }^{23}$ Ya en la década de los sesenta destacan los planes de reforma impulsados por Antonio Tavira y Almazán, conocedor de la Salmantina desde dentro. Dicho proyecto de reforma, también fallido, basaba su actuación en determinados ejes como reformulación de estatutos y nuevos planes de estudios, fuerte control regio por medio de visitadores, más poder para el rector y menos para el maestrescuela, nuevo sistema de oposición de cátedras y mayor modernización de las enseñanzas científicas. Se trata, en definitiva, de una reforma que confía Tavira -como todos los ilustrados- vendría impulsada desde arriba. ${ }^{24}$

El reinado de Carlos III pasará a la historia por ser el primero en que se emprende seriamente la tarea de adecuación de la Universidad a los nuevos tiempos. En este sentido, las disposiciones reformistas carolinas tienen como principal objetivo que la institución universitaria salmantina restablezca en su modernidad el prestigio de épocas anteriores. Prueba de ello es el conocido Plan de $1771^{25}$, que tanta importancia tuvo en cada uno de los aspectos de la vida universitaria. Conviene destacar aquí tres elementos institucionales: el nuevo sistema de elección de rector, la reducción del poder del maestrescuela y de su jurisdicción ${ }^{26}$, y, por último, las reformas en los diferentes planes de estudios. Más adelante, en el reinado de Carlos IV hay un repliegue de los aspectos reformistas, debido en gran medida al contexto histórico del momento. La presencia de la Revolución Francesa y el estado de oposición u hostilidad latentes entre diferentes percepciones vitales explican la reducción rítmica que experimentaron los cambios ilustrados. ${ }^{27}$

En definitiva, el siglo podemos estructurarlo en dos etapas: una primera, que englobaría los reinados de los dos primeros Borbones, esto es, hasta 1759, de corte tradicionalista, si bien con presencia de rigurosos intentos reformistas de características propias lo que ha dado lugar a que se denominen a estos años como de Antiguo Régimen Preilustrado; ${ }^{28}$ y una segunda, que engloba esencialmente el reinado de Carlos III de propiedades renovadoras y no revolucionarias, innovando comportamientos y formas de enseñanza que suponen con absoluta certeza el desmoronamiento de la universidad tradicional salmantina.

Durante el s. XIX, la universidad clásica queda anulada y diluida, estableciéndose en su lugar un sistema burocrático, liberal y centralista que mediante sucesivas regulaciones administrativas requerirá el derecho de dominio y pertenencia de las diferentes universidades. De ahí que nuestro estudio institucional quede aquí cerrado, dado que la producción documental de los nuevos tiempos, tan vinculada a los resortes administrativos

22 Ibídem, pp. 249-252. Son numerosas las ayudas que la Salmantina realiza a los ejércitos de Felipe $V$ y que este investigador analiza. Las fuentes que utiliza son fundamentalmente Registros de Claustros y de Cuentas.

${ }^{23}$ Para Macanaz vid. MARTín GAITE, C. El proceso de Macanaz. Madrid, 1970. (Cfr. PESET REIG, M. y PESETE REIG, J.L. "Las reformas ilustradas..." Op. Cit., pp. 146-149).

24 "Plan que para la Universidad de Salamanca escribió el doctor Tavira por orden del Ilmo. Señor Don Pedro Rodríguez de Campomanes... (28 de julio de 1767)" en SAUGNIEUX, J. La Ilustración cristiana española. Escritos de Antonio Tavira (1737-1807). Salamanca, 1986, pp. 109-122.

${ }^{25}$ Plan general de estudios dirigido a la Universidad de Salamanca por el Real y Supremo Consejo de Castilla y mandado imprimir por su orden. Salamanca: Juan Antonio de Lasanta, 1772. Un estudio minucioso en PESET REIG, M. y PESET REIG, J.L. El reformismo de Carlos III y la Universidad de Salamanca. Salamanca, 1969.

${ }^{26}$ Vid. Real Cédula de 11 de diciembre de 1770 se estableció que el período rectoral fuera de dos años y que para ser rector se necesitaba ser doctor o licenciado; posteriormente en tiempos de Carlos IV, Real Cédula de 12 de mayo de 1790 se estableció que para ser rector era necesario tener cumplidos veinticuatro años de edad. (Cfr. RODRÍGUEZ CRUZ, Á. El oficio de Rector en la Universidad de Salamanca... Op. Cit.) Para el segundo aspecto, vid. Real Cédula de 26 de octubre de 1771 se redujo la intervención del cancelario en regular el traje de los estudiantes que iban a matricularse; más tarde, por Real Cédula de 31 de octubre del mismo año, se especifican cuáles son sus obligaciones poniéndose de manifiesto la pérdida del poder adquirido en otras épocas. (RODRÍGUEZ CRUZ, A. "EI nivel institucional. 2. Autoridades académicas..." Op. Cit., p. 377).

${ }^{27}$ Fundamental para esta época PESET REIG, M. y PESET REIG, J.L. Carlos IV y la Universidad de Salamanca. Op. Cit.

${ }^{28}$ Así lo denomina Juan Luis Polo en sus conclusiones. (La Universidad salmantina... Op. Cit., p. 594). 
e institucionales, cambie radicalmente respecto de los procedimientos practicados en el denominado "modelo clásico", objeto de este estudio. ${ }^{29}$ En este sentido, las regulaciones administrativas más importantes que centralizan, secularizan y uniformizan las universidades decimonónicas son las siguientes:

- $\quad$ Plan Caballero de 1807: Por primera vez un mismo Plan de Estudios es administrado uniformemente en todas las universidades españolas. ${ }^{30}$ Ello trajo consigo las primeras consecuencias de la universidad liberal: centralización y uniformismo en contra de las peculiaridades propias, detrimento de los poderes originales en beneficio de los cargos centralistas, intervención del gobierno en asuntos hasta entonces de carácter más privativo como cátedras o claustros y supresión de muchas de las denominadas universidades menores.

- Plan Pidal de 1845: Supuso el desarrollo del proyecto centralizador inspirado en el modelo francés, despersonalizando por completo los estudios de la Salmantina y su trayectoria docente peculiar. Son características de este plan la secularización, la libertad y la gratuidad de la enseñanza ${ }^{31}$.

- Ley Moyano de 1857. Basado sobre un proyecto moderado, supuso la consolidación del sistema centralista liberal. A partir de este momento, las universidades pasan a depender del Ministerio de Fomento a través de una Dirección General y un Real Consejo de Instrucción Pública, el rector es un cargo de designación ministerial, que a su vez elige a sus colaboradores, se asienta un cuerpo funcionarial nacional de catedráticos por oposición, y el sistema universitario nacional se organiza en diez distritos. Salamanca sólo será uno más, de talante provinciano, con la incordiante cercanía de Valladolid y, no muy lejos, el resolutivo distrito central madrileño. ${ }^{32}$

En definitiva, institucionalmente la Universidad deja los fundamentos tradicionales que la habían caracterizado para regirse y organizarse atendiendo a moldes liberales. Con la Ley Moyano la Universidad clásica muere y deja paso a la Universidad contemporánea que se gobierna según lo que se establezca desde Madrid y su omnipresente Universidad Central.

\section{Series documentales para el estudio del poder en el Archivo Universitario de Salamanca}

\subsection{Series documentales para los poderes suprauniversitarios}

Es sabida la constante inquietud y el consiguiente arbitraje de los poderes suprauniversitarios, tanto monárquicos como papales, en el Estudio salmantino. Recordemos que éste fue fundado por Alfonso XI allá por el año 1218, que los primeros criterios organizativos fueron regulados por Alfonso X el Sabio en 1254, y que dos siglos más tardes, las primeras Constituciones conocidas fueron otorgadas por Benedicto XIII en 1411, siendo

${ }^{29}$ Para un seguimiento de dichas regulaciones administrativas, vid. PESET REIG, M. "La enseñanza del Derecho y la legislación sobre Universidades durante el reinado de Fernando VII (1808-1833)" en Anuario de Historia del Derecho español, 1968, XXXVIII, pp. 220-375; ídem. "Universidad y enseñanza del Derecho durante las regencias de Isabel II (18331843)" en Anuario de Historia del Derecho español, 1969, XXXIX, pp. 481-544; y "EI Plan Pidal de 1845 y le enseñanza en las Facultades de Derecho" en Anuario de Historia del Derecho español, 1970, XL, pp. 613-651.

${ }^{30}$ El Plan se aprueba para Salamanca por Real Decreto de 5 de julio, y para el resto de las universidades por Real Cédula del día 12 del mismo mes. (Vid. PESET REIG, M. y PESET REIG, J.L. "Las reformas ilustradas."Op. Cit., pp. 183184; y MARTíN GARCíA, Ma J. "El ochocientos 1. "Op. Cit., pp. 188-190).

${ }^{31}$ Vid. PESET REIG, J.L. y PESET REIG, M. La Universidad española...Op. Cit., pp. 430-439.

${ }^{32}$ Madrid, Barcelona, Oviedo, Salamanca (integrado por las provincias de Salamanca, Ávila, Cáceres y Zamora), Santiago, Sevilla, Valencia, Valladolid y Zaragoza. (Cfr. Ibídem). 
unos años después definitivamente promulgadas por Martín $\vee$ en 1422, erigiéndose así en base de la estructura universitaria del modelo clásico salmantino.

Siguiendo a Rodríguez-San Pedro, en la continua interjección suprauniversitaria que tiene como protagonistas a Reyes y Pontífices, podríamos distinguir cuatro períodos ${ }^{33}$ :

- $\quad$ uno primero, en el que la iniciativa es tomada por activos reyes medievales (Alfonso IX, Fernando III, Alfonso X);

- un segundo momento, en el que el protagonismo es compartido entre monarcas y pontífices, por lo que ha sido calificado como de transición en la participación gubernativa suprauniversitaria (Alfonso X, Alejandro IV, Sancho IV, Bonifacio VIII, Fernando IV, Clemente V, Alfonso XI, etc.);

- una tercera etapa, donde los pontífices, con la promulgación de las Constituciones, se convierten en los principales resortes externos de poder (Benedicto XIII y Martín $\mathrm{V})$;

- y un cuarto y último momento, en el que a medida que el poder de los pontífices retrocede, la autoridad monárquica se acrecienta. Los visitadores y reformadores son altos exponentes de esta nueva situación, y los Estatutos los complementos de las Constituciones en la regulación de la vida universitaria. Se trata de la etapa más extensa, abarcando los siglos XVI, XVII y XVIII, esto es, los momentos más gloriosos de la institución salmantina. Más tarde, Carlos III, en un intento de adaptar la Universidad a los nuevos tiempos, intentará disgregar los restantes resortes eclesiásticos, antecedente de lo que sucederá con alto grado de éxito en el siglo liberal decimonónico.

Las series vinculadas al poder pontificio son, por un lado, las Constituciones y los privilegios apostólicos, y por otro, las relacionadas con la contribución económica en el diezmo eclesiástico por adjudicaciones pontificias. Las series las presentamos ordenadas siguiendo de cerca las actividades ejercidas por esta institución. Por eso, la primera se corresponde con los aspectos más generales y menos específicos, y cuyo poder normativo es máximo: las Constituciones. En un nivel más técnico se sitúan las Bulas y Breves con valor normativo y los Privilegios Pontificios.

Las Constituciones son, pues, la organización jurídica y administrativa otorgada por los Pontífices a la Universidad de Salamanca. Las primeras fueron dadas por Benedicto XIII en $1411^{34}$, bien cuidada en los contenidos y de características amplias. Sólo once años más tarde, Martín $\vee$ otorgará las Constituciones de 1422. ${ }^{35}$ Dispuestas y organizadas según el diseño de las anteriores -encontramos en no pocas ocasiones una coincidencia literal en títulos y contenidos- presenta un mayor desarrollo casuístico y una ordenación temática más conseguida, acabando por ser el marco jurídico de referencia de la Salmantina. Su confirmación o modificación era de único dominio del Papa. ${ }^{36}$

${ }^{33}$ Vid. RODRÍGUEZ-SAN PEDRO BEZARES, L.E. "Universidad y poder" y "Constituciones, Estatutos, Privilegios". En: La Universidad salmantina..., Op. Cit., vol. I, conjuntamente en pp. 291-341; y VALERO GARCÍA, P. "El nivel institucional 1. Gobierno estatutario". En: La Universidad de Salamanca..., Op. Cit., vol. II, pp. 325-353; etc.

${ }^{34}$ Al parecer, es conocida la existencia de una normativa anterior, fechada en 1381. (Cfr. VALERO GARCíA, P. "El nivel institucional 1. Gobierno estatutario".Op. Cit., pp. 328-330).

35 GONZÁLEZ DE LA CALLE, P.U. y HUARTE Y ECHENIQUE, A. Constitutiones Universitati Studiorum Salamantinae [...] anno millesimo quadrigentessimo undecimo. Zaragoza, 1932; ídem."Constituciones de la Universidad de Salamanca, 1422. Edición paleográfica" en Revista de Archivos, Bibliotecas y Museos. Madrid, 1935-36, vol. II-XXIX, pp. 217, 345 y 402; y vol. III-XXX, pp. 348. Más recientemente, GARCÍA, P. y PÉREZ MARTíN, T. Constituciones de Martín V. Salamanca: Universidad, 1991 (con introducción, facsímil y traducción castellana de las Constituciones de 1422).

${ }^{36}$ MARTín V. Papa. Constitutiones in fauorem Studii Salmantini, 20 feb. 1422. Copias manuscritas: Ms. 209 (fols. 1 26), Año 1422 (original); Ms. 208 (fols. 9-34v.) Siglo XV; Ms. 210 (fols. 1-28v.) Siglo XV; Ms. 211 (fols. 16-42) Siglo XV; Ms. 212 (fols. 33-62v.) Siglo XVI; Ms. 2423 (fols. 2-21) Siglo XV; Constitutiones almae Academiae Salmanticensis. Salmanticae: Typ. 
Además del principal cuerpo legislativo pontificio, la Universidad de Salamanca disfrutaba de Breves, Bulas y Privilegios pontificios diversos. Se trata de documentos normativos y reglamentarios, que suelen tener un carácter concreto $\mathrm{y}$, en no pocas ocasiones, en forma de retoque correctivo o simplemente confirmatorio. Encontraremos una colección de Bulas en AUSA ${ }^{37}$ 2867. ${ }^{38}$ Asimismo, en nuestro análisis de la Colección de Papeles Varios hemos podido constatar su presencia en no poca cantidad repartidos por diversos volúmenes y legajos. ${ }^{39}$

Las series vinculadas al poder monárquico las ordenaremos de las que tienen un marco normativo más amplio a las más específicas que regulan los múltiples aspectos de la vida cotidiana y la administración de la Universidad.

Así, encontramos los Estatutos aprobados por el Consejo de Castilla. Según los estudiosos, cada reforma estatutaria alcanzada lleva detrás un largo proceso de maduración paulatina que incluye algunas tentativas malogradas con anterioridad. ${ }^{40}$ Los Reyes Católicos y el robustecimiento de la monarquía autoritaria ocasionó que los monarcas intervinieran cada vez más, siempre mediante el Consejo de Castilla, en los asuntos y materias universitarias. Así, los controles regios tomaron la forma de visitadores periódicos (D. Tello de Buendía, D. Diego Ramírez de Villaescusa, D. Pedro Pacheco, D. Alonso Mexía, D. Juan de Córdoba, D. Diego Enríquez de Almansa D. Hernán Pérez, el licenciado Montalvo, D. Diego de Covarrubias, D. Pedro López Arrieta, el Ldo. Villagómez, el Ldo. Jaraba, D. Pedro Velarde, D. Juan de Zúñiga, D. Juan Álvarez de Caldas, D. Roco Campofrío, D. Gilimón de la Mota, etc.) con autoridad para adecuar los Estatutos a las circunstancias del contexto, corrigiéndolos cuantas veces fueran necesarias. Recordemos, no obstante, que el marco jurídico de referencia siguió siendo las Constituciones Pontificias de 1422, a las que se fueron adicionando los Estatutos de 1538, 1561, 1594, 1604 y 1618, culminándose con la Recopilación general de 1625, la cual se constituirá en una dúctil narración jurídica hasta 1711 y las posteriores reformas liberales del siglo XIX. ${ }^{41}$

Nebrissensis, ca. 1487-90. BUSA 1.250; Constitutiones tam commode apte; quam sancte alme Salmanticensis academiae toto terrarum orbe florentissime. Salamanca, 1538. BUSA 57184(1); Constitutiones tam commodae aptaeque; quam sanctae almae Salmanticensis academiae toto terrarum orbe florentissimae. Salmanticae: Ioannes Maria à Terranoua, 1562. BUSA 57081(1); Constitutiones tam commodae aptaeque; quam sanctae almae Salmanticensis academiae toto terrarum orbe florentissimae. Apud haeredes Matthiae Gastij, 1584. BUSA 57080(1); Constitutiones apostólicas y Estatutos de la muy insigne Vniversidad de Salamanca. Salamanca: Diego Cusio, 1625. BUSA 57179; Constituciones de la Vniversidad de Salamanca (1422) Ed. de P.U. González de la Calle y a. Huarte y Echenique Op. Cit. BUSA 56407(2) y 67215; Constituciones de Martín V para la Universidad de Salamanca Ed. Por Beltrán de Heredia, en Bulario...Op. Cit. nº 647. Además, BUSA 57180; BUSA 57191 y BUSA 57.192 (varios ejemplares impresos).

${ }^{37}$ Mantendremos la signatura antigua, si bien en algunos casos especificaremos igualmente la signatura numérica nueva. Nos adaptaremos así al Cuadro de signaturas que unánimemente siguen los investigadores en Historia de la Universidad de Salamanca.

${ }^{38}$ Breve de Julio II confirmando las Letras de sus predecesores Eugenio IV e Inocencio VIII sobre el cargo de Conservador de la Universidad de Salamanca. 1505. AUSA 2867(11); Breve de Pío V dando facultades a la Universidad de Salamanca para poder tener el Santísimo y la Extremaunción en la Capilla del Hospital del Estudio, y concediendo indulgencia plenaria a todos los pobres que muriesen en dicho Hospital. 1571. AUSA 2867(2); Breve de Sixto V mandando a la Universidad de Salamanca haga un nuevo índice de los libros prohibidos y lo envíe urgentemente a Roma. 1587. AUSA 2867 (3); Breve de Gregorio XIV disponiendo que los monasterios, colegios, etc. y cualesquier personas, aunque exentas de pagar diezmos, paguen las tercias a la Universidad de Salamanca. 1591. AUSA 2867 (4), etc. (Vid. BELTRÁN DE HEREDIA, V. Bulario... 3 vols.).

39 Uno de los más repetidos es el privilegio de Eugenio IV, o "Eugeniana", que permitía la jubilación a los catedráticos que hubiesen enseñado veinte años en cátedras de propiedad. Hay bastantes ejemplos: AUSA. P.V. 140 "Copia de Bula de Gregorio XIII acerca de que el Maestrescuela deba conocer en lo referente a las causas matrimoniales, beneficiales y de simonía, expedido en 1582"; AUSA. P.V. 141 "Copia de Bula de Benedicto XIII en que concede para siempre a la Universidad de Salamanca las dos partes de las tercias de la Armuña, Baños y Peña de Rey"; AUSA. P.V. 142; AUSA. P.V. 143; P.V. 144; etc. (Cfr. VIVAS MORENO, A. Fondos documentales del Archivo Histórico de la Universidad de Salamanca. La Colección de Papeles Varios... Op. Cit., Vols. III, IV y VI).

40 Vid. RODRÍGUeZ-SAN PEDRO BeZARES, L.E. "Constituciones, Estatutos, Privilegios". En: La Universidad salmantina del Barroco... Op. Cit., vol. I, p. 306.

${ }^{41}$ VALERO, P. "Gobierno estatutario". En: La Universidad de Salamanca... Op. Cit., vol. II, pp. 335-348. 
Se hallan ubicados en el Archivo Universitario salmantino una interesante recopilación de Estatutos manuscritos -incluidas algunas revocaciones y confirmaciones de los años 1560, 1561, 1575, 1594, 1604, 1618, 1621, 1624 , $1625,1632,1653$, y $1749 .{ }^{42}$ Se trata, por consiguiente, de un legajo con los manuscritos originales de las principales reformas estatutarias de la Universidad con signatura AUSA 2885. ${ }^{43}$ Al mismo tiempo, como ya vimos, algunos de los Estatutos han recibido estudios y ediciones específicas. ${ }^{44}$

Por su parte, encontramos los Planes de Estudios aprobados por el Consejo de Castilla. Se trata de textos normativos que regulan las materias, métodos, lecturas y requisitos para la obtención de los diferentes grados académicos. Se corresponden, por consiguiente, con preceptos de organización interna de carácter fundamental para la administración docente universitaria. Los principales Planes de Estudios de la Universidad de Salamanca fueron el de 1538, el de Covarrubias de 1561, el de Zúñiga de 1594 y el plan carolino y reformista de $1771 .{ }^{45}$

El primer planteamiento formal lo encontramos en los Estatutos de 1538. Ciertamente se trata de un esquema incipiente, pero de principios consistentes. Prueba de ello es que sirvió de base para el posterior de Covarrubias. Éste se caracteriza por presentar la casuística de forma más organizada y completa. Las lecturas de los catedráticos van segmentadas por facultades, cursos y asignaturas para cada año. El rigor era tan exhaustivo que se precisaba incluso las materias y lecturas que debían explicarse en el aula cada dos meses. Por su parte, el Plan de Estudios de Zúñiga de 1594 es aún más minucioso. Utiliza el mismo esquema de distribuciones que el

${ }^{42}$ Estatutos de don Diego Rodríguez Almansa, con confirmación real de 23 de octubre de 1560, 37 ff., sin encuadernar (incompleto: sólo LII títulos); "Estatutos originales hechos y ordenados en la Visita que hizo desta Vniv[ersida]d el muy ilustre S[eño]r D[o]n Diego Cobarrubias de Leyba. Obispo de Ciudad Rodrigo, los quales confirmó la Mag[estad] de Phelipe Seg[un]do. Confirmáronse en Ma[dri]d a 15 de octubre de d[ic]ho año. Año 1561", 91ff., encuadernados en pergamino; "Processo de los nuebos Estatutos hechos y ordenados por el muy Illustre señor liz[encia]do D[o]n Pedro Velarde, Reformador y Visitador desta Vniv[ersida]d. En Sal[a]m[an]ca a 16 de Setiembre de d[ic]ho. Año de 1575", 114 ff. Sin confirmación. Se trata de deliberaciones para la confección de nuevos Estatutos; "Año de 1594. Estatutos originales hechos y ordenados por esta Univ[ersida]d siendo su Visitador el Se[ño]r L[icencia]do D[o]n Juan de Zúñiga del Conxejo de Su M[a]g[esta]d en el de la S[an]ta Inquisición; y aprobados por el Conxejo. Aprobáronse en el Pardo a 29 de Octubre de d[ic]ho año", con confirmación de 29 de octubre de 1594. 63 ff., sin encuadernar; Estatutos del D[octo]r Álvarez de Caldas, con confirmación real en 28 de febrero de 1604, 8 ff., sin encuadernar. Además, 13 ff, correspondientes a los Estatutos redactados por la Universidad, antes de la confirmación: "Estatutos que hizo y ordenó esta Univ[ersida]d para su govierno, siendo su visitador el S[eño]r D[octo]r Juan Álvarez de Caldas del Consexo de su M[a]g[esta]d en el se la Santa y G[enera]l Inquisición. A 17 de Abril del d[ic]ho año. Año de 1602"(incompleto); "Estatutos nuebos. L[icencia]do Gilimón de la Mota, 1618", con confirmación real en 20 de octubre de 1618. 6 ff., sin encuadernar; Provisión Real de 16-II-1621, revocando los Estatutos 25, 26 y 30, sobre que no pudiesen votar en cátedras estudiantes de diversas facultades, 2 ff.; Estatuto compuesto por la Universidad y hecha pública en enero de 1624, "tocante a que los proveídos de cátedras de sustitución habían de regentar seis meses al menos dichas cátedras, y que sólo se entendiese ser catedrático el que lo fuese por oposición", 3 ff.; Provisión Real de 15-I-1625, confirmando ciertos Estatutos redactados por la Universidad sobre la entrada de catedráticos al examen de licenciados. 4 ff.; Provisión Real de11-XII-1632, declarando Estatutos sobre la provisión de cátedras de leyes, 4 ff.; Estatutos de la Universidad de Salamanca de 1653, en la visita del Licenciado D. Diego Ribera Báñez. Copia del s. XVIII. Sin confirmación del Consejo; y Estatutos de la Universidad de Salamanca de 1749. Sin confirmación del Consejo.

${ }^{43}$ También encontramos Estatutos manuscritos en BUSA Por orden cronológico son los siguientes: BUSA 57183 (1), BUSA 57183 (2), BUSA 57184 (7), BUSA 57184 (4), BUSA 57184 (5), BUSA 57184 (6), BUSA 57184 (8), BUSA 57183 (3), BUSA 57080 (2), BUSA 57095 y BUSA 57182. (Cit. SANTANDER, T. "Fuentes para una historia de la Universidad de Salamanca". Op. Cit., pp. 300-301). Además, 41 ff. fechables hacia 1530 en Ms. 218.

${ }^{44}$ Vid. cronológicamente FUERTES HERREROS, J.L. Estatutos de la Universidad de Salamanca. 1529. Mandato de Pérez de Oliva. Rector. Salamanca, 1984; ALEJO MONTES, F.J. La reforma de la Universidad de Salamanca a finales del siglo XVI: Los Estatutos de 1594. Salamanca: Universidad, 1990 (Vid. Apéndices, pp. 107-185); RODRÍGUEZ-SAN PEDRO BEZARES, L.E. (Estudio y ed.) Estatutos hechos por la Universidad de Salamanca (1625). Salamanca: Eds. Universidad de Salamanca, 1990.

${ }^{45}$ Cfr. CARABIAS TORRES, A. Ma. "Docencia: facultades, Planes de Estudios, cátedras, grados y método didáctico". En: Colegios Mayores: Centros de poder. Los Colegios Mayores de Salamanca en el s. XVI. Salamanca: Universidad de Salamanca, 1986, 3 vols,, vol. I, pp. 282-302; PESET REIG, M. y PESET REIG, J.L. El reformismo de Carlos III... Op. Cit.; RODRÍGUEZ CRUZ, Á. "Régimen docente". En: La Universidad de Salamanca... Op. Cit. Vol. II, pp. 448-449; RODRÍGUEZSAN PEDRO BEZARES, L.E. "Planes de Estudios". En: La Universidad salmantina del Barroco... Op. Cit. Vol. II, pp. 350-404; etc. 
de Covarrubias, aunque cambia y complementa las asignaciones. Las reformas posteriores (Caldas y Gilimón de la Mota) fueron mínimas y en la recopilación de 1625 se mantiene el Plan de Zúñiga, si bien con varias inclusiones de los anteriores. Por último, el Plan de 1771 adopta ciertas variaciones tanto en materias y métodos como en lecturas y requisitos para la obtención de los grados. Ejemplo claro fueron los manuales de enseñanza. ${ }^{46}$

Por último, contamos con las Provisiones, Cédulas y otros Privilegios Reales. Se trata de documentos normativos otorgados por los monarcas, que rigen múltiples y diferentes asuntos de la vida académica. La serie de documentos reales ocupa las signaturas AUSA 2869-2883. Al mismo tiempo, tienen una fuerte impronta en la Colección de Papeles Varios. ${ }^{47}$

\subsection{Series documentales para los claustros académicos}

Son "reuniones periódicas, y a veces extraordinarias, de las autoridades universitarias, presididas por el rector y el maestrescuela, para el gobierno y administración de la Universidad". Se trata, por consiguiente, del principal organismo interno de poder, con capacidad para determinar en todo excepto en lo relativo al fuero académico y a la colación de grados mayores, que eran funciones exclusivas del Maestrescuela. Encontramos dos series surgidas de esta función: por un lado, los Libros de Claustros o Registros de Claustros, que se constituyen como fuente principal para la historia de la Universidad, y que son reflejo de las deliberaciones y acuerdos adoptados por los organismos directores en los claustros pleno, de rector y consiliarios, de diputados, y de Primicerio (hasta septiembre de 1606); y, por otro, los Libros de Claustro de Primicerio, que es una pequeña serie que comienza en 1607 hasta 1854, dado que se decide componer un registro especial con los acuerdos tomados en el claustro de Primicerio que, al parecer, se archivaría en el arca.

Los Libros de Claustros guardan una gran parte de la historia de la Universidad de Salamanca a partir del año 1464. A decir de Florencio Marcos son "fuente primaria, segura y auténtica, sólido cimiento sobre el que se puede y debe edificar esa magna historia [de la Universidad]" 48 , y, entre otros muchos historiadores que utilizan esta serie como referencia fundamental de sus investigaciones, Juan Luis Polo los califica de fuente necesaria para "una historia 'total' de la Universidad de Salamanca". ${ }^{49}$ Se trata de 269 volúmenes, con las signaturas AUSA 1-266. ${ }^{50}$ Comienzan en el año 1464 y se prolongan hasta el de 1834. Existen algunos vacíos, faltando los cursos 1480-1481 a 1501-1502, 1513-1514 a 1524-1525 y 1536-153751.

Los Libros de Claustros cubren el denominado periodo anual del cargo rectoral, es decir, de San Martín a San Martín, esto es, de 11 de noviembre a 10 de noviembre del siguiente año, que era cuando se elegía nuevo

${ }^{46}$ Plan general de Estudios dirigido a la Universidad de Salamanca por el real y Supremo Consejo de Castilla, y mandado imprimir de su orden. Salamanca: Antonio Villagordo y Alcaraz y Thomás García Honorato, 1771. AUSA 2879; Reglamentación y planes de Estudios de la Universidad de Salamanca y sus Facultades. Reales Provisiones, Cédulas y Órdenes de reforma de enseñanza (1553-1875). AUSA 2032. Además en BUSA 57102, BUSA 57089, BUSA 57110, BUSA 57196, etc.

47 Provisiones, cédulas y demás documentos reales referentes a la Universidad de Salamanca. AUSA 2869-2883. Reúne documentos reales desde 1388 a 1800. También en BUSA 44587, BUSA 57089, y BUSA 56989. (Vid. BELTRÁN LLERA, J. ; GUTIÉRREZ GARRIDO, G.; MARTÍN MARTíN, J. Y RODRÍGUEZ ROJO, M. Regesta de los documentos reales... Op. Cit.). Además hay un compendio de bulas y privilegios reales en Ms. 210, Ms. 211 y Ms. 212. Para Papeles Varios, por ejemplo vid. AUSA P.V: 3-35; P.V. 3-55; P.V. 12-48, etc.

${ }^{48}$ MARCOS RODRÍGUEZ, F. Extractos de los Libros de Claustros.... Op. Cit, p. 7.

${ }^{49}$ POLO RODRÍGUEZ, J.L. La Universidad salmantina..., Op. Cit., pp. 59-60. "Los claustros de diverso carácter que pueblan las actas (plenos, de diputados, de rector y consiliarios, del Colegio Trilingüe), generan un mosaico de informaciones que hacen posible el conocimiento a fondo de la Universidad y la elaboración de una historia global de la misma". (p. 60)

Las signaturas antiguas tenían tres números bis (AUSA11; AUSA 243; y AUSA 244) por lo que las signaturas de Libros de Claustros termina con las nueva signatura en AUSA 269.

${ }^{51}$ P. Valero indica lo siguiente: "[...] cabe señalar la existencia de una laguna que va desde 1533 (AUSA 11) a 1538 (AUSA 12) y que sólo muy parcialmente está cubierta por el duplicado AUSA 11 bis" ("Libros de Claustros". En: La Universidad de Salamanca en la época de Carlos V...Op. Cit., p. 20). 
rector. ${ }^{52}$ Están presentes en diversas disposiciones normativas, pero es Diego de Covarrubias quien verdaderamente les valora institucionalmente y les concede alcance. ${ }^{53}$

Por otro lado, dichos registros son confeccionados por la escribanía o Secretario del Estudio, notario oficial que administrará prácticamente todos los registros. En un principio, esto es, hasta 1538, al frente de ella estaba un escribano nombrado por el rey. Sin embargo, el titular de la escribanía no intervenía para nada en la redacción y escritura de estos libros; en consecuencia, los que realmente desempeñaban este oficio eran uno o más notarios nombrados por el titular de la escribanía, quienes actuaban, por tanto, como delegados suyos. A partir de los Estatutos de 1538, el Secretario era nombrado por el claustro pleno, según se recogía en los Estatutos de Covarrubias (1561) y posteriormente incluido en la Recopilación (1625). ${ }^{54}$

Respecto a la veracidad de los contenidos que se ofrecen en esta fuente documental, el hecho de que el cargo de Secretario se transfiriera durante grandes períodos hereditariamente de padres a hijos, careciera de críticas su función notarial, y gozara de los apoyos económicos del Claustro siempre que los solicitaba ha querido ser visto como prueba de su objetividad informativa. ${ }^{55}$ Sin embargo, por otro lado, la constante supervisión de los Visitadores Reales, y el grave cuidado con el que se debía formalizar una fuente que medía -y pulsaba- todos y cada uno de los aspectos de la vida institucional universitaria muestra algunas sospechas acerca de la total ingenuidad de las informaciones ofrecidas en dichos registros. ${ }^{56}$ En cualquier caso, lo que queda fuera de toda duda es que se trata de una fuente primaria y básica para el conocimiento institucional universitario.

En otro orden de cosas, los libros guardan un orden cronológico, si bien las alteraciones no son raras. Primero se escribía un borrador o apunte, en el que se debía indicar los asistentes al claustro y los asuntos tratados. El secretario para ello se servía de algunos oficiales, que le ayudaban a trascribir telegráficamente la reunión para que pudiera ser firmada al final de la sesión por el rector y el doctor más antiguo, tal y como estaba instituido. ${ }^{57}$ Sin embargo, al parecer, esta normativa unas veces no se cumplía -dada la dificultad de preparar en tan breve espacio de tiempo la redacción-, y otras, los borradores -que se realizaban en papeles sueltos- se perdían, hecho que ocurría con demasiada frecuencia. En este caso, encontramos en Libros de Claustro una doble casuística: que los apuntes perdidos aparezcan después de la siguiente reunión claustral que ya ha ido copiada en el Libro de Claustros, subsanándose en este caso el error poniendo a lo ya escrito la letra "b" y a lo que ha

52 Hay variantes. Por ejemplo, los tres Libros de Claustros del s. XV y los primeros del s. XVI abarcan varios años. El que los Libros de Claustros sólo cubrieran un año es fruto de los Estatutos de 1538, concretamente su título X. Por otra parte, a partir de 1705 es frecuente que cada Libro de Claustro abarque dos años. Además, a veces hay irregularidades, del tipo que no comience el libro en San Martín sino "en Domingo de Quasimodo" por no haber acudido el rector por el 11 de noviembre (por ejemplo, el año 1607).

53 "Ítem, ordenamos y mandamos que el escrivano haga un libro en cada un año que empieze con cada retor nuevo, para escrivir los que al claustro vinieren y las cosas que en él se determinaren, y lo que en este libro no pareziere asentado sea de ningún valor. El qual libro, cu[m]plido el dicho año, se ponga en el archivo público destinado por la Vniversidad, de manera que en cada un año aya su libro que pase del escrivano del claustro al archivo público, y no salga el dicho libro ni libros del claustro a do estuviere del archivo." (Recopilación de Estatutos... IX, 11).

"Estatuimos y ordenamos que, antes que entren en el dicho claustro, el vedel que ansí llamó, sea obligado a dar la cédula de llamamiento al escrivano, so pena de dos reales, y el escrivano, so la dicha pena, antes que se empieze el claustro, lea la cédula en el dicho claustro públicamente, que lo oyan todos, y póngala y asiéntela en el libro por la cabeza del claustro que se hiziere, so pena de dos reales que le sean executados en su salario por cada vez que la dexare de asentar y se hallare no aver asentado o leído la dicha çedula." (Ibídem, IX, 10).

"Mas en el libro del claustro se asienten los votos particulares. Y si los que votaren aparte quisieren testimonio de sus votos, que se les dé queriéndolo seguir por justicia." (Ibídem, IX, 23).

"Ítem, estatuimos que, acabado el claustro y escrito en el libro todo lo que en él se ha determinado, el retor y dotor más antiguo revea[n] lo determinado y firmen en el dicho libro, sin salir del dicho claustro, y el escriuano abaxo d[e] él." (Ibídem, IX, 22).

54 Covarrubias (LVII, 9). (Cfr. RODRÍGUEZ CRUZ, A. "El nivel institucional..." Op. Cit., pp. 391-392).

${ }^{55}$ Así lo expone Polo Rodríguez para la época 1700-1750 donde Diego García de Paredes dejó en 1725 el cargo a su hijo. Además, se les concedieron licencias temporales de ausencia y se les prestó ayuda económica en no pocas ocasiones. (POLO RODRIGUEZ, J.L. "Fuentes para una historia 'total' de la Universidad de Salamanca". En: La Universidad Salmantina... Op. Cit., p. 60).

56 Rodríguez-San Pedro matiza la veracidad de los registros claustrales. (Cfr. "Fuentes". En: La Universidad Salmantina...Op. Cit., vol. I, pp. 60-61).

${ }^{57}$ Covarubias (X, 16). 
aparecido y se copia tarde con la letra "a", constando así el orden en el que debieran estar en el Registro; o que los apuntes perdidos aparezcan después de varias reuniones claustrales, no quedando más remedio que copiarlos sin respetar el orden. Incluso en algunos Libros de Claustros encontramos algunos folios agregados o intercalados, fruto de haber copiado ya uno o varios claustros que, con buen criterio, debieran ir ordenados cronológicamente después. En cualquier caso, no es extraño que se explique el orden en nota. ${ }^{58}$

En referencia a la estructura informativa que presentan los Libros de Claustros, podemos decir que se ofrecen algunos datos repetitivos: día, mes y año de celebración de la sesión; nombre del rector o vicerrector; relación de doctores, maestros y catedráticos; llamada del bedel; y relación por el escribano de lo tratado en la sesión. De forma más ocasional: nombre del lugar de la sesión; nombre de los Visitadores Reales; y nombre del notario si lo tratado lo hiciera aconsejable por su importancia. ${ }^{59}$

Sin embargo, la presencia de datos constantes no impide que, con frecuencia, la información se nos presente de manera desigual, en ocasiones sin orden ni concierto, y sin precisión en los contenidos. Una noticia no se conoce en su desarrollo completo, sino que, podemos carecer del conocimiento de su origen, o bien ignorar su desenlace. Lo más común es poseer datos inconexos y que los asuntos se diluyan tras ser deliberados, pues pasan a solventarse por otras vías: comisarios, pleitos, tribunal del maestrescuela, etc. Además, son comunes los temas recurrentes, tales como asuntos de préstamos pecuniarios, deudas retenidas, reiteración de acuerdos, conflictos de poder, promulgación de normas, etc. En definitiva, los Libros de Claustros son sumamente interesantes, justamente por lo heterogéneo de su información, resultando ser cardinales para la confección de la historia de la institución.

La segunda serie, desprendida de esta primera desde septiembre de 1608, son los Libros de Claustro de

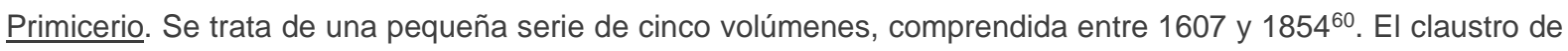
Primicerio es el formado por doctores y maestros presididos por un prior o Primicerio, elegido anualmente el día de San Martín. Gozaba de un cargo más honorífico que real, esto es con cierta representatividad, aunque con atribuciones limitadas. ${ }^{61}$ El claustro de Primicerio poseía una frecuencia de reunión muy limitada, oscilando normalmente entre una y cinco convocatorias anuales. El lugar de reunión solía ser la Capilla de San Jerónimo. Los Libros de Claustros de Primicerio tratan asuntos de protocolo, fiestas, colaciones, propinas, prisiones de doctores por diversos motivos, cartas de recomendaciones, adorno y obras de la Capilla de San Jerónimo, actos y cultos de dicha Capilla, préstamos del arca de Primicerio, etc. Sus actas eran certificadas por el secretario de la Universidad.

\subsection{Series documentales para el Maestrescuela y la Audiencia Escolástica}

El Maestrescuela era el representante simbólico del poder Pontificio en la institución universitaria. Como administrador de la jurisdicción apostólica, pronto llegó a ser una de las más importantes autoridades académicas, ostentando dos de las más relevantes funciones universitarias: por un lado, la colación de grados precediendo al rector en las ceremonias-, y por otro, la jurisdicción civil y criminal sobre el Estudio, convirtiéndose así en juez supremo y, en consecuencia, con poder de amonestar, castigar y excomulgar. ${ }^{62} \mathrm{Al}$ mismo tiempo, entre sus funciones se encontraba la de hacer valer y respetar las Constituciones y Estatutos universitarios, compeliendo a los diferentes oficiales y autoridades académicas la observancia de las obligaciones de su cargo. Tenía poderes, entre otros, para desterrar a cualquier escolar, o para conceder o rehusar licencias de bachilleres de pupilos y visitar anualmente los pupilajes de éstos ${ }^{63}$. Además, tenía por misión asistir a juntas, claustros y demás órganos colegiados, era uno de los claveros del Arca Universitaria y

${ }^{58}$ Cfr. RODRíGUEZ-SAN PEDRO BEZARES, L.E. “Fuentes”. En: La Universidad Salmantina... Op. Cit., Vol. I, pp- 5960.

${ }^{59}$ Vid. VALERO, P. "Libros de Claustros" Op. Cit., pp. 20-21.

60 AUSA 836-840.

${ }^{61}$ Tenía como funciones: convocar a doctores y maestros a los actos que le son propios, ocupar el primer puesto en los actos y reuniones en que el colegio de doctores intervenga, atender la dirección de la citada corporación, organizar los festejos académicos (procesiones y actos de Capilla, honras y entierros, comidas de toros, etc.), y estar a cargo del arca del colegio pudiendo realizar préstamos de ella. (Cfr. RODRÍGUEZ-SAN PEDRO BEZARES, L.E. "Primicerio". En: La Universidad Salmantina... Op. Cit., Vol. I, pp. 401-404. Igualmente: VALERO, P. "Claustro de Primicerio". En: La Universidad de Salamanca... Op. Cit., pp. 25-26).

${ }^{62}$ Constituciones de Martín V... Op. Cit., XXII-XXIII.

${ }^{63}$ Vid. Zúñiga (LXVIII, 1-3); Covarrubias (LXVI). 
guardaba el sello de la corporación estudiantil. Su jurisdicción fue mantenida hasta su supresión en 1832. Por otra parte, el cancelario contaba para ejercer su potestad con su Audiencia, para la que designaba juez, fiscal, procurador, notarios y alguacil, disponiendo asimismo de cárcel propia. ${ }^{64}$

El Juez era el segundo del Maestrescuela, con amplios poderes recogidos en los Estatutos: en las causas criminales debía examinar personalmente a los testigos, visitar las Escuelas con objeto de remediar las posibles revueltas y bullicios, e incluso, con posibilidad de desterrar de la universidad a los escolares que de forma perseverante molestaban en las lecciones, etc. ${ }^{65}$

Respecto a la cárcel escolástica, no en pocos momentos estuvo carente de organización. Rodríguez-San Pedro nos cuenta cómo en época de Felipe III la situación fue calificada como de lamentable: sin supervisiones periódicas, sin registro de entrada, con descuidos en los procesos judiciales, con retenciones indebidas, etc. Ante tal abusiva situación, Zúñiga intentó potenciar una antigua agrupación, denominada 'cofradía de estudiantes presos' -que había sido creada en 1568 y se encontraba fuera de servicio-, que estaría formada por seis doctores y seis estudiantes, los cuales visitarían frecuentemente la cárcel con el fin de evitar los abusos, agilizar los procesos y recaudar fondos para satisfacer las necesidades de los recluidos. Al parecer, con el paso del tiempo, la cofradía se puso en funcionamiento, la cárcel se aderezó, y posteriormente, tras diversos intentos y fracasos, se trasladó de lugar. 66

Por otra parte, es conveniente recordar que el Maestrescuela, como autoridad pontificia y vitalicia, en el ejercicio de sus atribuciones tropezaba constantemente con el rector. Así pues, de alguna forma, la historia de la maestrescolía constituye una larga serie de conflictos con el rector, dado que las cuestiones de competencias entre las dos autoridades académicas surgían casi a diario. ${ }^{67}$

Pero, sin más detenimiento, veamos las series documentales procedentes de estas actividades:

- $\quad$ Pleitos de la Audiencia Escolástica: Cuenta con no menos de 352 legajos,

constituyéndose como una de las series de mayor prestigio. Sus fechas extremas son 1547-183568. Se trata de los intrincados, y a veces extensos, expedientes del tribunal escolástico por múltiples y diferentes cometidos. La información que en ellos aparece, al decir de todos los estudiosos, debe ser de una fenomenal valía, esencialmente para aquellos aspectos de carácter social y de vida cotidiana, que particularmente

${ }^{64}$ Vid. entre otros ALEJO MONTES, F.J. "El maestrescuela". En: La Reforma de la Universidad de Salamanca a finales del siglo XVI... Op. Cit., pp. 37-42; RODRÍGUEZ CRUZ, Á. "Régimen docente”. En: La Universidad de Salamanca..., Op. Cit. Vol. II, pp. 373-381; RODRÍGUEZ-SAN PEDRO BEZARES, L.E. "El maestrescuela y su jurisdicción”. En: La Universidad salmantina del Barroco... Op. Cit., vol. I, pp. 381-401; SÁNCHEZ y SÁNCHEZ, D. "El oficio del maestrescuela en la Universidad de Salamanca: luces y sombras en el ejercicio del cargo en el siglo XVI". En: Salamanca y su proyección en el mundo... Op. Cit., pp. 61-81; y VALERO GARCíA, P. "Maestrescuela". En: La Universidad de Salamanca en la época de Carlos V. Op. Cit., pp. 59-83. De forma especial: ALONSO ROMERO, $\mathrm{M}^{\mathrm{a}}$. P. Universidad y sociedad corporativa. Historia del privilegio jurisdiccional del Estudio salmantino...Op. Cit.

65 Véase: Zúñiga (LXVIII "De la Audiencia y oficiales del Maestrescuela"); "Item estatuimos, que el juez del Maestrescuela examine por su persona los testigos en las causas criminales, y si por algún impedimento legítimo no lo pudiere hacer, no cometa el examen de los testigos a solo el notario, sino que juntamente con él se cometa a otra persona" (Zúñiga (LXVIII, 17)); "Item, que porque hay algunos estudiantes inquietos, que en los generales, y en las puertas de ellos desasosiegan a otros, y impiden las lecciones: estatuimos que el maestrescuela envíe su juez, por lo menos una vez cada semana, a las escuelas, que vea las lecciones de curso, y si oyen, y están con sosiego, o se andan paseando por las escuelas, y se informe de los catedráticos, y personas graves de lo que en esto pasa, y si tuviere noticia que algunos inquietan, y desasosiegan las lecciones, los reprenda, y si no se enmendaren, los destierre de la Universidad." (Zúñiga (LXVIII, 7)).Podía vender libros de los estudiantes incriminados (Zúñiga (LXVIII, 9)), efectuar registros (Zúñiga (LXVIII, 11)), apresar (Zúñiga (LXVIII, 2), absolver (Zúñiga (LXVIII, 13), etc. Son fundamentales los apartados de la obra de ALONSO ROMERO, Ma P. "Naturaleza de la jurisdicción escolástica" y "El Maestrescuela y su audiencia". En: Universidad y sociedad corporativa... Op. Cit., pp. 221-236 y 268-288 respectivamente.

66 Vid. RODRÍGUEZ-SAN PEDRO BEZARES, L.E. "El Maestrescuela y su jurisdicción". En: La Universidad Salmantina... Op. Cit., I, pp. 385-387. También: ALONSO ROMERO, Mª P. "La cárcel". En: Universidad y sociedad corporativa... Op. Cit., pp. 286-287.

${ }^{67}$ Vid. ALONSO ROMERO, Ma P. "El modelo salmantino: Títulos de jurisdicción y facultades del Maestrescuela. El Maestrescuela-Cancelario". En: Universidad y sociedad corporativa... Op. Cit., pp. 236-252.

${ }^{68}$ AUSA 2999-3351 
son los más ausentes en el resto de las series documentales. Quedan representados en esta documentación todas las controversias y desavenencias junto a la problemática jurisdiccional, la cual se presenta como un bajo continuo en la historia de la institución universitaria. Recordemos que la jurisdicción escolástica lo era tanto civil como criminal y extensiva a todo el gremio universitario; en consecuencia ante ellas se informaban y clarificaban pleitos por múltiples y diferentes asuntos. ${ }^{69}$ Desde un punto de vista interno los más frecuentes representarán fricciones de carácter económico -bien sobre rentas y censos, bien sobre alquileres, compras, etc.-, actitudes de delincuencia -alborotos, desórdenes, robos, peleas, muertes, etc.-, o discordias por oficios y beneficios de doctores o maestros. Asimismo, también los hay por otras cuestiones relacionadas con la moralidad, las costumbres y conductas, o el protocolo. No obstante, los conflictos más destacados emanan de las disputas competenciales con autoridades civiles y religiosas externas a la administración universitaria en estricto sentido. Sin duda alguna, los colegiales mayores engendrarán numerosos enfrentamientos con motivo de su posición hegemónica y diferencial. Pero, al mismo tiempo, habrá pugnas entre la jurisdicción escolástica y la eclesiástica contextual y las de las órdenes militares y jueces de cruzada, dados los niveles fronterizos de sus respectivas facultades, o imbricaciones contra las diversas jurisdicciones civiles, bien sea frente a la administración central, bien contra los juristas o el corregidor de Salamanca por diferentes conflictos de poder. ${ }^{70}$

- $\quad$ Libro de Documentación, informes y consultas de la jurisdicción del Maestrescuela. Se trata de un libro con fechas extremas $1508-1792^{71}$. Se refieren numerosos documentos, a veces de gran extensión, sobre competencias de jurisdicción entre el rector y el maestrescuela, entre el maestrescuela y el claustro, entre las autoridades eclesiásticas y civiles y el maestrescuela etc., destacando sobre otros puntos los referentes al ejercicio de la maestrescolía, sus prerrogativas, el orden de precedencia, etc. En realidad, esta documentación no reúne las características para ser calificada de serie documental, dado que simplemente resulta ser un conjunto facticio de diferentes agrupaciones documentales que obedecen a diversos motivos, si bien todos ellos proceden de la función jurisdiccional ejercida por el Maestrescuela.

Al margen, contamos con otro libro que reúne la sentencia e informes varios acerca del pleito del Tribunal de la Rota sobre exención de jurisdicción episcopal del Maestrescuela, con fechas extremas 1583-1629 y con signatura ${ }^{72}$. En realidad, se trata de un compendio de documentos originados por esta causa, y, por tanto, todos ellos vinculados a las disputas motivadas por cuestiones de atribuciones jurisdiccionales.

Al margen de la documentación procedente directamente del Maestrescuela y su Audiencia, encontramos otra documentación originada por el tribunal del Administrador dedicada especialmente a dilucidar los pleitos de rentas. Ya vimos al analizar la función hacendística cómo al Administrador le correspondía gestionar los bienes y rentas del Estudio y la capacidad para proceder judicialmente contra los deudores de la Universidad ${ }^{73}$. Con el correr del tiempo, y a medida que el Mayordomo fue cumplimentando sus importantes funciones, el Administrador acentuará sus características de Juez de Rentas o Juez Apostólico-Administrador, poseyendo tribunal y poder de censuras y dilucidando los pleitos de rentas. ${ }^{74}$ De esta forma, ante el tribunal del administrador se llevarán pleitos de tercias, censos, casas arrendadas, etc. produciéndose, en ocasiones,

${ }^{69}$ Vid. ALONSO ROMERO, Ma P. "El maestrescuela y su jurisdicción". En: Universidad y sociedad corporativa... Op. Cit., pp. 221-304.

${ }^{70}$ Vid. RODRíGUEZ CRUZ, Á. "Régimen docente". En: La Universidad de Salamanca..., Op. Cit. Vol. II, pp. 376-377; RODRÍGUEZ-SAN PEDRO BEZARES, L.E. "Problemas de jurisdicción”. En: La Universidad salmantina del Barroco... Op. Cit., pp. 394-400; y SÁNCHEZ y SÁNCHEZ, D. "El oficio del maestrescuela en la Universidad de Salamanca: luces y sombras en el ejercicio del cargo en el siglo XVI". En: Salamanca y su proyección en el mundo... Op. Cit., pp. 67-72. Es muy curioso el capítulo que refiere Daniel Sánchez en estas páginas cuando habla del enfrentamiento entre la justicia seglar y la escolástica universitaria.

71 AUSA 2891. Intitulado: Documentación referente a la jurisdicción del Maestrescuela de la Universidad de Salamanca. Consultas, informes, concordias, etc.

72 AUSA 2890. Intitulado: Sentencia del Tribunal de la Rota sobre exención de jurisdicción episcopal del Maestrescuela de la Universidad de Salamanca. Varios informes sobre la misma cuestión.

${ }^{73}$ Zúñiga (XLVIII, 6)

${ }^{74}$ Zúñiga (XLVI, 3). 
enfrentamientos y fricciones con la jurisdicción escolástica. ${ }^{75}$ En consecuencia, la principal razón de ser del Juez de Rentas será la protección del sistema de ingresos, esencialmente la proveniente del cereal, para la cual, las Constituciones le conceden una jurisdicción especial. ${ }^{76}$ Se constituye así en el dirigente destacado de un Tribunal compuesto además por un fiscal y un notario, que son los encargados de la tramitación de los expedientes.

Por todo ello, la información proveniente del Juez de Rentas resulta muy atractiva a los investigadores. La documentación hallada referente a Pleitos del Juez de Rentas es un sólo libro índice de los pleitos que por razón de tercias tuvieron lugar, con fechas extremas 1659-171077. La presencia de un único libro de características sumariales, y que además cubre tan pocos años, podría ser debida a la complejidad orgánica institucional universitaria, que ocasiona -sin por ello cuestionarnos el marco general de las atribuciones del Juez de Rentasque encontremos algún otro oficio que desempeñe paralelamente los mismos cometidos, o al menos determinados asuntos no clarificados suficientemente: nos referimos, como podremos ver a continuación, a la Junta de Pleitos. Por consiguiente, no será descabellado pensar que parte de los pleitos del Juez de Rentas se encuentren ubicados en la documentación procedente de la Junta de Pleitos o en otras series documentales complementarias y entre los propios legajos de la Audiencia Escolástica.

Aparte de los pleitos procedentes orgánicamente de la Audiencia Escolástica y del Tribunal del Administrador, encontramos otros procesos que hemos preferido exponer por separado, a pesar de ser conscientes de la dificultad archivística que ello comporta dado que en algunos casos siguen dependiendo del Maestrescuela o del Juez de Rentas. Tienen aquí cabida, en consecuencia, otras series documentales procedentes de la Junta de Pleitos de Hacienda u otras complementarias sobre diezmos y primicias, escrituras de concordias y ejecutorias de pleitos.

Así, contamos con los Libros de actas de la Junta de Pleitos de Hacienda. Se trata de al menos 14 volúmenes, donde se recogen, como el propio nombre indica, las actas y acuerdos de la Junta de Pleitos. Sus fechas extremas son 1615-180178. Existe, no obstante, una laguna significativa que cubre toda la segunda mitad del s. XVII, exactamente desde el curso 1641-42 al 1717-18. La Junta de Pleitos fue creada por claustro de diputados del 31 de diciembre de 1615, con funciones poco clarificadoras relacionadas con la 'atención a la hacienda y los pleitos de la Universidad'. En realidad, en su origen fue un organismo de apoyo en el que el claustro descargaba de forma circunstancial parte de sus funciones de carácter hacendístico y jurisdiccional, delegaciones que, con el tiempo, se hicieron definitivas. En un principio, estaba integrado por cuatro miembros: un Administrador, un Contador, un Síndico y un doctor jurista. En la primera mitad del siglo XVIII, ya fueron tres los doctores -por regla general dos juristas y un teólogo- los componentes que la formaban, escogidos en claustro de diputados entre los graduados de doctor. Se reunirían todas las semanas y a cambio de sus servicios recibirían un salario. Más tarde, en 1782, se acuerda que sean cinco los miembros, aunque en 1791, se rebajaron a tres, siempre con la

75 "En agosto de 1600, el Maestrescuela hará saber que el administrador únicamente tenía competencias en 'tercias y décimas' $y$, a continuación, se entablará un largo pleito con censuras y requisas de papeles. La postura del claustro se inclina en favorecer una jurisdicción extensa del administrador en cuestiones de hacienda general [...] el asunto se prolonga, se lleva a la Chancillería y se pone en 1602 en conocimiento del visitador Caldas. La sentencia resultará favorable al administrador, manteniéndose un latente resquemor en el maestrescuela, volviendo a aflorar el problema en determinadas ocasiones". (RODRÍGUEZ-SAN PEDRO BEZARES, L.E. "Administrador”. En: La Universidad salmantina del Barroco... Op. Cit., vol. I, p. 494. Por su parte, Juan Luis Polo nos refiere los conflictos con el obispo de Salamanca, el propio Maestrescuela o la justicia real, la cual acabará sometiendo al oficio del Juez de Rentas. (POLO RODRíGUEZ, J.L. La Universidad Salmantina... Op. Cit., p. 86).

76 "[...] por lo qual se ha ordenado al Administrador, el que fuera en su tiempo y por la autoridad apostólica, que a todos, y a cada uno de los deudores del decimal de la Universidad, a los arrendatarios y fiduciarios y detentadores o ocupantes de los mismos, y no a qualquier otro contradictor y rebelde, que mediante censuras eclesiásticas u otros procedimientos del derecho, obligue, compele y retenga, incluso con invocación al brazo secular [...]" (Constituciones de Martín V... Op. Cit., X (Cit. y trad. de MÉNDEZ SANZ, F. "La jurisdicción de rentas: Juez de Rentas y su tribunal". En: La Universidad salmantina de la Ilustración... Op. Cit., p. 20, nota 8)).

77 AUSA 2029. Lleva por título: Libro índice de los Pleitos que por razón de Tercias tiene la Universidad de Salamanca.

${ }^{78}$ AUSA $2949-2962$ 
presencia de, al menos, un jurista. ${ }^{79}$ Para la cuestión que ahora nos abate, conocemos que inspeccionaba directamente los arrendamientos del Estudio, colaborando de forma eficaz con el Juez de Rentas -llegando, en ocasiones, a reunir toda la información al respecto y liderando verdaderamente el proceso-, que era, a la postre, el facultado para despachar con la justicia ordinaria de la zona donde residía el deudor para que se procediera contra él. ${ }^{80}$ Por consiguiente, resulta ser ésta una serie complementaria de la del Juez de Rentas en aquellos casos en que la Junta de Pleitos tramita los expedientes que le correspondían a dicho Juez.

También contamos con los Libros de pleitos sobre diezmos y primicias: Se trata de dos unidades de instalación, con fechas extremas 1416-180281. Contamos con un vacío para el curso 1647-48. Se refieren fundamentalmente los pleitos entre la Universidad de Salamanca y los defraudadores en el pago de tercias, especialmente con aquellas instituciones privilegiadas o particulares pudientes. Se trata de expedientes, algunos de ellos de bastante extensión, que con frecuencia se alargaban en el tiempo por el empeño de las partes involucradas. Hemos de tener en cuenta que los pleitos decimales comportaban grandes gastos (salarios, compulsas, retribución de los comisarios, ayudas de costas, despachos, etc.), y que si para un particular común podían llegar a endeudarle, para el clero - que tenía posibilidades de traspasar los procesos de unas instancias a otras- éstos consistían sustancialmente, no tanto en la cuenta de los diezmos y primicias cuanto en el derecho y la existencia de precedentes, convirtiendo los pleitos en debates inagotables. ${ }^{82}$ Según Rodríguez-San Pedro y Polo Rodríguez son varias las causas de los pleitos y diligencias en que se ve envuelta la Universidad por razón de diezmos y primicias: intromisión de la Corona en la libre percepción de los diezmos y primicias de la Universidad, impedimentos a los arrendatarios por las justicias locales, fraudes de las comunidades regulares y órdenes militares, falsificaciones de instituciones y particulares, y fraudes de tercias de renteros de heredades. Todas ellas están representadas en esta serie documental.

Además, el archivo dispone de Escrituras de Concordias con comunidades y corporaciones: Se trata de dos volúmenes, con fechas extremas 1527-1829. ${ }^{83}$ Las Escrituras de Concordia, al menos en teoría, representan el fin de los litigios entre la institución universitaria y las comunidades regulares, estipulándose, entre otros muchos asuntos, los derechos de ambas partes sobre las rentas decimales. Sin embargo, el fraude de tercias de las comunidades regulares que tienen concertadas concordias con la Universidad continuó existiendo. Dicho fraude tenía múltiples estampas, aunque la más común es que las concordias habían quedado anticuadas con el paso del tiempo, dado que cuando se firmaron no se tenían en cuenta las tierras adquiridas con posterioridad o no estaban incluidos arrendamientos que se estaban operando entre otras cuestiones. En definitiva, las condiciones de la concordia habían cambiado, para lo cual normalmente se faculta a la Junta de Tercias para que extinga las antiguas y concierte nuevas concordias, ocasionándose así largos y porfiados pleitos. En la presente serie se unifican en dos volúmenes las diferentes concordias firmadas con las diferentes comunidades religiosos y corporaciones civiles, donde se tocan los múltiples puntos que pudieran ocasionar fricciones o desavenencias. ${ }^{84}$

Por último, encontramos Ejecutorias de pleitos litigados. Se trata de dos volúmenes. El primero de ellos trata estrictamente sobre ejecutorias diversas de pleitos litigados por la Universidad de Salamanca, especialmente sobre el pago de diezmos y tercias, con fechas extremas 1551-1635 y con signatura y el segundo es un índice incompleto de pleitos litigados del s. XVIII, con signatura. Son, pues, series complementarias de las anteriores. ${ }^{85}$ Reúne las resoluciones de los procesos litigados. Su principal característica es que se emiten como un mero

${ }^{79}$ Cfr. MÉNDEZ SANZ, F. "La jurisdicción de rentas: Juez de Rentas y su tribunal". En: La Universidad salmantina de la llustración. 1750-1800. Hacienda y reforma. Salamanca: universidad de Salamanca, 1988, pp. 20-23.

${ }^{80}$ Cfr. Ibídem; POLO RODRíGUEZ, J.L. "Los claustros y las Juntas, la toma de decisiones”. En: La Universidad salmantina del Antiguo Régimen... Op. Cit. pp. 76-77; y RODRÍGUEZ-SAN PEDRO BEZARES, L.E. "Juntas especiales”. En: La Universidad salmantina del Barroco... Op. Cit., I, pp. 516-517.

${ }^{81}$ Signaturas AUSA 2964-2965.

${ }^{82}$ MÉNDEZ SANZ, F. "Las tercias reales". En: La Universidad salmantina de la llustración..., Op. Cit., pp. 34-41; POLO RODRÍGUEZ, J.L. "Pleitos de tercias y defraudación". En: La Universidad salmantina del Antiguo Régimen... Op. Cit., pp.124-128; RODRÍGUEZ-SAN PEDRO BEZARES, L.E. "Pleitos y deudores". En: La Universidad salmantina del Barroco... Op. Cit., I, pp. 532-536, etc.

${ }^{83}$ Signaturas AUSA 2970-2971.

${ }^{84}$ Cfr. MÉNDEZ SANZ, F. Ibídem p. 40 y ss.; POLO RODRÍGUEZ, J.L. Ibídem, p. 127; y RODRÍGUEZ-SAN PEDRO BEZARES, L.E. Ibídem.

${ }^{85}$ AUSA 2997, titulado: Ejecutorias diversas de pleitos litigados por la Universidad de Salamanca, especialmente sobre pago de diezmos y tercias. AUSA 2998, titulado: Índice de pleitos litigados por la Universidad de Salamanca. 
dictamen. Normalmente no se explicitan los motivos o fundamentos de derecho que se han aplicado, limitándose a dar por bien probada o por no probada la demanda de una de las partes. El escribano levantaba acta y comunicaba a las partes -si así lo solicitaban- las resoluciones. ${ }^{86}$

\subsection{Series documentales para el estudio del poder en las instituciones vinculadas.}

El estudio del poder en las instituciones vinculadas a la Salmantina debe ser también mencionado, siquiera de forma generalista en estas páginas. El tema ha sido tratado de forma genérica en la historiografía. Sobre el Colegio Trilingüe encontramos buenas panorámicas de Ana María Carabias ${ }^{87}$. Los Colegios seculares han sido un tema que siempre ha estado en boga. Destacan las décadas de los años 50 y 60 , época en la que proliferaron numerosos trabajos alentados y coordinados por la figura de Luis Sala Balust. ${ }^{88}$ Más recientemente, Ana María Carabias ha desarrollado diversos trabajos, todos ellos rigurosos, vinculados a los Colegios Mayores: estudios institucionales y de poder, catálogos de estudiantes y proyección americana entre otras numerosas cuestiones son profusamente analizadas. ${ }^{89}$ Por otra parte, disponemos de escasos estudios sobre los Colegios Militares. Contamos con alguna panorámica dispersa de José Gómez Centurión y A. Ma Carabias Torres, amén de otros análisis parciales. En cuanto a los colegios regulares carecemos de perspectivas panorámicas que analicen la vinculación con la institución salmantina. Sin embargo, excepción hecha de algunas incursiones panorámicas ${ }^{90}$, abundan monografías y artículos sobre conventos individuales y sobre los numerosos frailes que impartieron sus clases en el Estudio salmantino. En este sentido, predominan los estudios concernientes a los Dominicos de San Esteban y sus frailes y al el Colegio Real de la Compañía de Jesús.91

${ }^{86}$ Cfr. POLO RODRÍGUEZ, J.L. Ibídem, p. 128; y RODRÍGUEZ-SAN PEDRO BEZARES, L.E. Ibídem.

${ }^{87}$ Especialmente: CARABIAS TORRES, A. Ma. "Evolución histórica del Colegio Trilingüe de Salamanca: 15501812" en Stvdia Histórica. Historia Moderna. Salamanca, 1983, vol. I, nº 3, pp. 143-168.

${ }^{88}$ Por citar algunas: Catálogo de fuentes para la historia de los antiguos Colegios seculares de Salamanca. Madrid, 1954; Reales reformas de los antiguos Colegios de Salamanca anteriores a las del reinado de Carlos III (1623-1770). Valladolid, 1956; Visitas y reformas de los Colegios Mayores de Salamanca en el reinado de Carlos III, Valladolid, 1958; "Los antiguos Colegios de Salamanca y la matrícula universitaria" en Hispania Sacra. 1959-60, vol. XII, no 23, pp. 131-164; "Las primeras Constituciones del Colegio de San Bartolomé de Salamanca, copia de los primeros Estatutos del Colegio de San Clemente de Bolonia" en Miscelánea Antonio Pérez Goyena. Estudios Eclesiásticos. 1960, no 35, pp. 253-263; etc.

${ }^{89}$ El Colegio Mayor de Cuenca en el siglo XVI: Estudio institucional. Salamanca: Universidad, 1983; "Los colegiales mayores salmantinos en el gobierno de las Indias (siglo XVI)" en Res Gesta. Rosario, 1983, n 13, pp. 23-30; "Catálogo de Colegiales del Colegio Mayor de Oviedo (siglo XVI)" en Stvdia Histórica. Historia Moderna. Salamanca, 1985, vol. III, nº 3, pp. 63-105; "Catálogo de Colegiales del Colegio Mayor de San Bartolomé (siglo XVI)" en Salamanca. Revista Provincial de Estudios. Salamanca, 1985-86, no 18-19, pp. 223-282; Colegios mayores: Centros de poder. Los Colegios Mayores de Salamanca durante el siglo XVI. Salamanca: Universidad, 1986. 3 vols.; "El poder de las letras. Colegios Mayores salmantinos en la administración americana." En: Primeras Jornadas sobre la presencia universitaria española en la América de los Austrias (1535-1700). Alcalá, 1987, pp. 2-28; "Notas sobre las relaciones entre el Estado y la Universidad en la España moderna" en Stvdia Histórica. Historia Moderna. Homenaje al Prof. M. Fernández Álvarez. Salamanca, 1989, vol. III, pp. 707-721; "Catálogo de colegiales del Colegio Mayor de San Bartolomé (1700-1840)" en Stvdia Historica. Historia Moderna, 1991, IX, pp. 43-88; "Excolegiales mayores en la administración española y americana durante el reinado de Felipe V" en Estudios de Historia Social y Económica de América, 1991, 7, pp. 55-93; "El ocaso político de los colegiales mayores en Indias (1746-1830)" en Estudios de Historia Social y Económica de América, 1992, 4, pp. 107-117;

$9^{0}$ GARCÍA ORO, J. "Las reformas pretridentinas en los Colegios Religiosos de Salamanca" en Stvdia historicoecclesiastica. Festgabe für Prof. Luchesius G. Spätling O.F.M. herausggeben von Isaac Vázque O.F.M.. Roma, 1977, pp. 613-656; MAZO VIVAR, A. del; FRADES MORERA, Ma J. Crónica de la desolación: retazos del patrimonio conventual salmantino. Salamanca: Diputación Provincial, 1994.

${ }^{91}$ Sobe el Colegio Dominico: CUERVO, J. Historiadores del Convento de San Esteban de Salamanca. Salamanca, 1914-16. 3 vols.; BELTRÁN DE HEREDIA, V. "El convento salmantino de San Esteban en Trento" en La Ciencia Tomista. 1948, 15, pp. 5-54; "El convento de San Esteban en sus relaciones con la Iglesia y la Universidad durante los siglos XIII, XIV y XV" en La Ciencia Tomista. 1957, 84, pp. 95-116; CARRO, V. Los Dominicos y el Concilio de Trento. Salamanca, 1948; ESPINEL MARCOS, J.L. San Esteban, historia y guía, siglos XIII-XX. Salamanca, 1978 (2 ${ }^{\mathrm{a}}$ ed. Salamanca: Editorial San Esteban, 1995); HERNÁNDEZ, R. "Convento y estudio de San Esteban". En: La Universidad de Salamanca... Op. Cit., vol. I, pp. 369-381; RIESCO, F. "La imprenta en el convento de San Esteban de Salamanca" en La Basílica Teresiana, 1919, IV, pp. 346-351. Sobre el Colegio Jesuita: GARCÍA DOMínGUEZ, L...Ma. Vida religiosa y estudios en el Colegio Real de la 
Dicho esto, encontramos documentación concerniente al gobierno y poder del Colegio Trilingüe, reservada a las funciones directivas del colegio. Se reúnen aquí los reglamentos y los corpus normativos que rigen todos los aspectos de la vida colegial. De este modo, s ubican en el archivo:

- Estatutos: Se trata de una regla que tiene fuerza de ley para el gobierno de la corporación, siendo aprobados por claustro de diputados. Como hemos visto, sus reformas son continuas e incluidas en los diferentes Estatutos de la Universidad. Los encontramos ubicados junto a los Estatutos manuscritos de la Universidad de Salamanca. ${ }^{92}$

- Libros de Visitas: Los comisarios visitadores eran nombrados por el claustro de diputados o por el claustro de cabezas y catedráticos de propiedad, también denominado claustro del Colegio Trilingüe. El visitador se constituye como el órgano intermedio entre la institución universitaria y la entidad colegial, teniendo por función la supervisión de los acuerdos de gobierno tomados por los claustrales, la inspección y control del Colegio y de la gestión de su vicerrector, y el cumplimiento -y modificación si procede- de los Estatutos que lo regularizan. Las visitas eran realizadas por lo general por el rector de la Universidad, el visitador y dos doctores o maestros catedráticos. A través de ellas, se debía vigilar de forma estricta todo lo referente al Trilingüe y, de este modo, inspeccionar cualquiera de las esferas de la vida de sus ocupantes. De viva voz, se interrogaba al vicerrector -poniendo en tela de juicio algunas de sus actuaciones-, a los colegiales -sobre cualquier aspecto de la vida material y espiritual-, y a los sirvientes sobre sus funciones y servicios-. Además, para evitar imprecisiones u olvidos voluntarios se debían inspeccionar todas las dependencias del edificio. En consecuencia, de la lectura de esta serie se obtiene multitud de información, fruto de la reglamentación de los diferentes ámbitos que componen la vida social y cotidiana en el colegio y el consiguiente interrogatorio. Así pues, encontramos datos sobre cuentas, salarios, gastos ordinarios y extraordinarios, exámenes, becas, conflictos internos, oficios, obras y mantenimiento, raciones, etc. ${ }^{93}$ Lamentablemente, aunque los Estatutos mandaban que las visitas se realizaran cada cuatro meses ${ }^{94}$, lo cierto es que sólo se efectuaron ocasionalmente y con motivo de problemas coyunturales (intentos de restar gastos, enmendar abusos, etc.). Se han localizado tres libros, con fechas extremas 1554-1588. El primero, con las visitas de 1554-60; el segundo, con las de 1560-72; y el tercero, con las visitas de 1574-88. No se encuentra, por tanto, la correspondiente al año 1573. A partir de 1588 no se han localizado libros de visitas. La razón, según esgrime Carabias Torres, a juzgar por la información que se extrae de una visita llevada a cabo en 1777, es que éstas desde entonces no existieron tal y como venían reguladas en los Estatutos, esto es, mediante la formulación de diferentes y exhaustivas preguntas a los diferentes

Compañía de Jesús en Salamanca (1665-1700). Universidad Pontificia, memoria de licenciatura. Salamanca, 1983, inédita; HERNÁNDEZ MONTES, B. "El Colegio de la Compañía y la Universidad de Salamanca en el siglo XVI" en Stvdia Historica. Historia Moderna. Homenaje al Profesor Manuel Fernández Álvarez. Salamanca, 1989, III, pp. 723-744; "Extrañamiento de los Jesuitas de Salamanca en el año 1767". En: Salamanca y su proyección en el mundo... Op. Cit., pp. 283-317; MUÑOZ DELGADO, V. "Zumel (1540-1607) y los Jesuitas" en Estudios, 1961, XVII, 53, pp. 229-248; RODRíGUEZ GUTIÉRREZ DE CEBALLOS, A. Estudios del Barroco salmantino. El Colegio Real de la Compañía de Jesús (1617-1779). Salamanca, 1969 (reed., 1985); TELLECHEA IDÍGORAS, J.I. "EI Real Colegio de la Compañía de Salamanca y las Misiones Populares (16541766)" en Salmanticensis, 1975, XXII, pp. 297-332, etc.

92 AUSA 2885“Processos de los nuebos Estatutos hechos y ordenados por el muy Ilustre Señor Lize[ncia]do D[o]n Pedro Velarde, Reformador y Visitador de [e]sta Vniver[sida]d" fols. 51r.-55v.; Zúñiga (LXIV); Caldas (LXV). Además, el título correspondenciente al Colegio Trilingüe de los "Estatutos nuebos de Gilimón de la Mota" de 1618 (f. $5 \mathrm{v}$.), y la "Real Cédula sobre los nuebos Estatutos de la Visita y reformación que de la Universidad hizo el Señor Don Diego de Rivera. Año de 1623", sin foliar. Asimismo, hay documentos normativos en otras series documentales. Por ejemplo, en el Libro de Visitas 2133, fol. $9-11 v$.

${ }^{93}$ De interés para su modelo organizativo: POLO RODRíGUEZ, J.L. "Hacienda del Colegio Trilingüe". En: La Universidad Salmantina... Op. Cit., pp. 90-93.

94 "[...] que el Colegio fuera visitado por el retor con el maestro o maestros que la Vniversidad nombrare, de quatro en quatro meses". (Vid. Covarrubias (LXIV, 25)). 
miembros del Trilingüe. Al parecer, tras las incertidumbres de finales del s. XVI y el s. XVII, las visitas realizadas sólo se tradujeron documentalmente en breves informes que hacían y custodiaban los propios visitadores, los cuales no se trasladaban a ningún libro, sino que únicamente se daba lectura de ellos en claustros. En consecuencia, las visitas de que disponemos para el s. XVIII, que se encuentran en el legajo AUSA 2161, son muy pocas y breves, tal y como corresponde a un documento de juicio que debía repasarse en claustro de forma diligente. ${ }^{95}$ En definitiva, los libros de visitas son de enorme valía para el s. XVI al recoger datos de enorme diversidad, constituyéndose como una fuente de importancia primordial, pues quedan en ellas reflejados hasta los detalles más nimios de la vida cotidiana.

- Al margen, contamos con diferentes Acuerdos y decretos para el Gobierno del Colegio Trilingüe: En realidad no se trata de una serie documental, sino de diecinueve páginas impresas, que no se encuentran tal y como dijera Sala Balust por error -y que ya corrigió Carabias Torres- en la sección de manuscritos de la Biblioteca Universitaria de Salamanca, sino que se ubican en la sección facticia de Papeles Varios $N^{0} 44$ (fols. 204-213) ${ }^{96}$. Se trata de nuevos ordenamientos para los Visitadores, desarrollándose una exhaustiva normativa. Se legislan aspectos de gobierno, asuntos hacendísticos y programas de costumbres, vida de piedad y actos comunitarios. Por consiguiente, se encuentra muy vinculado a las series precedentes y fundamentalmente a los Libros de Claustros.

Respecto a los restantes colegios encontramos una importante dispersión documental. La localización en el AUSA de la documentación de los plurales archivos de los colegios, más allá de lo que estos autores han investigado, resultaba inviable: la casi ausencia de instrumentos de descripción del archivo, la abundante documentación que se encuentra en espera de tratamiento archivístico, la formidable dispersión que han sufrido los múltiples archivos de los colegios y conventos incorporados y la heterogeneidad de la documentación obligaría, en honor a la verdad y a la seriedad del trabajo, a investigaciones duraderas, que nos desplazarían, con mucho, de lo que ahora pretendemos. En cualquier caso, el estudio del poder colegial reúne las siguientes series documentales, reservadas a los textos fundacionales y cuerpos legislativos -tanto los dados por el fundador como los que se van adhiriendo a ella posteriormente-, prerrogativas reales y pontificias, y gobierno interno.

Destacan las Constituciones, que son las leyes fundamentales y normas organizadoras de la entidad colegial, inherentes al concepto de ordenamiento que todo miembro del colegio tiene la obligación de obedecer. Son pues, los fundamentos básicos y permanentes (desde la fundación hasta la extinción) de la legislación colegial; los Estatutos, que son el ordenamiento jurídico que rige la organización a corto plazo, completando o matizando lo que dicen las Constituciones, esto es, el conjunto de normas inferidas de la adaptación de los preceptos constitucionales al contexto de los tiempos, conferidas a sí mismo por los propios colegiales o aquellas miembros con cualidades de gobierno (visitador, patrón, administrador, etc.); y las Ceremonias, que resultan ser la regulación absoluta de la vida cotidiana colegial y sus costumbres, adaptándose al día, sobre contenidos muy concretos y encaminadas a hacer destacar a los colegiales del resto de los estudiantes. Otros documentos pontificios (bulas y breves) o de otra jerarquía eclesiástica, junto a provisiones, cédulas y documentos reales componen el poder supracolegial. Además, como gobierno interno, contamos con libros de capilla o de

${ }^{95}$ AUSA 2133-2135La visita de 1777 citada (también en AUSA 2161) es la más espaciosa que se conoce. Ello se debe a que fue encargada directamente por el rey con motivo de las importantes reformas universitarias de entonces. (Cfr. CARABIAS TORRES, A. Ma. "Evolución histórica del Colegio Trilingüe de Salamanca: 1550-1812" en Stvdia Historica. Historia Moderna..., p. 148).

96 "Acuerdos y decretos que para el gobierno del Colegio Trilingüe de la Universidad de Salamanca se instituyeron y renovaron en la visita general que se hizo en el presente año de 1720 por comisión del claustro de 15 de enero y 11 de mayo de este año por los señores don pablo Victoriano Calderón. Nuevamente reimpresas por Comisión de el claustro de Señores Cabezas y Cathedráticos de Propiedad por comisión de 15 de junio de 1747...". Según el cuadro de signaturas realizado en nuestra tesis doctoral para la Colección de Papeles Varios, corresponde con P.V. 44 - 22. (Cfr. SALA BALUST, L. Catálogo de fuentes para la historia de los antiguos colegios seculares de Salamanca... Op. Cit., n 380 , p. 58; VIVAS MORENO, A. Fondos documentales... Op. Cit., vol. IV). 
acuerdos, juntas y capítulos, y libros de visita. Lamentablemente, según los estudios de Sala Balust y Carabias Torres mucha de esta documentación se ha perdido. ${ }^{97}$

\section{Conclusiones}

El estudio del poder de la institución universitaria salmantina ha sido desarrollado de forma profusa, variada y desigual. Hay abundantes estudios sectoriales, si bien faltan estudios comparativos y síntesis colectivas.

El análisis del poder universitario refiere documentación procedente del Archivo Histórico Antiguo, esto es, aquél que guarda la documentación formada por documentos fundacionales, Constituciones, privilegios y bulas pontificias; Estatutos, provisiones, cédulas y privilegios reales; títulos de propiedad y escrituras de rentas; censos y ejecutorias. Asimismo, describe documentación de la Secretaría del Estudio, esencialmente lo concerniente al gobierno interno con especial mención a las series emanadas de los claustros académicos. Del mismo modo, cuenta con documentación procedente de la Audiencia Escolástica, que es la que resulta de la función tutelada por el Maestrescuela y su Audiencia. Y, por último, con documentación de las múltiples y variadas procedencias de las instituciones vinculadas -esencialmente colegiales-, que, naturalmente, generan una documentación para el estudio de sus estructuras de gobierno y poder.

Se han identificado las series documentales para el estudio del poder de las instituciones universitarias durante los ss. XVI-XVIII, es decir, para el denominado modelo clásico universitario. Entendemos, en este sentido, que el modelo salmantino puede ser exportado -con alguna salvedad- al modelo universitario Hispánico. Dichas series son:

1. Autoridad pontificia: constituciones, bulas, breves y privilegios pontificios;

2. Autoridad real: estatutos, planes de estudios, provisiones, cédulas y privilegios reales;

3. Claustros académicos: libros o registros de claustros y libros de claustros de primicerio;

4. Maestrescuela y Audiencia Escolástica: pleitos de la Audiencia Escolástica, libros de documentación, informes y consultas de la jurisdicción del maestrescuela, pleitos del juez de rentas, libros de actas de la junta de pleitos de hacienda, libros de ppleitos sobre diezmos y primicias, escrituras de concordias con comunidades y corporaciones y ejecutorias de pleitos litigados;

5. Colegio Trilingüe: estatutos, libros de visitas, acuerdos y decretos;

6. Colegios vinculados: documentos fundacionales, constituciones, estatutos, ceremonias, bulas, breves y otros documentos de jerarquía eclesiástica, provisiones, cédulas y otros documentos reales, libros de capilla o libros de acuerdos, juntas y capítulos y libros de visitas.

97 Vid. CARABIAS TORRES, A. Ma. "Estudio institucional a la luz de las Constituciones, Estatutos y Ceremonias". En: El Colegio Mayor de Cuenca... Op. Cit., pp. 81-160, concretamente, pp. 83-94; ídem. "Los cuerpos legislativos". En: LoS Colegios Mayores de Salamanca..., Op. Cit., p. 454-473. 


\section{Referências}

ALEJO MONTES, F. Javier. "La reforma educativa de Juan de Zúñiga en la Universidad de Salamanca (1594)" en Historia de la Educación. Revista interuniversitaria, 9, 1990, pp. 183-196.

ALEJO MONTES, F. Javier La Reforma de la Universidad de Salamanca a finales del siglo XVI: los estatutos de 1594. Salamanca: Ediciones Universidad de Salamanca, 1990.

ALEJO MONTES, F. Javier La Universidad de Salamanca bajo Felipe II: 1575-1598. [Valladolid], Junta de Castilla y León, 1998.

ALONSO ROMERO M. P. "Sobre la jurisdicción y el gobierno de la Universidad de Salamanca a fines del siglo XVI" en Stvdia Histórica. Historia Moderna. Salamanca: Ediciones Universidad de Salamanca, nº XI, 1993, pp. 117-147.

ALONSO ROMERO, M. P. Universidad y sociedad corporativa: Historia del privilegio jurisdiccional del Estudio salmantino. Madrid: Tecnos, 1997.

BELTRÁN DE HEREDIA, V. Bulario de la Universidad de Salamanca (1218-1549). Salamanca, 1966-67, 4 vols.

BELTRÁN DE HEREDIA, V.Cartulario de la Universidad de Salamanca (1218-1600). Salamanca, 1970-73, 6 vols.

BELTRÁN DE HEREDIA, V. La Cancillería de la Universidad de Salamanca. Salamanca, 1954.

BELTRÁN DE HEREDIA, V. "El convento de San Esteban en sus relaciones con la Iglesia y la Universidad durante los siglos XIII, XIV y XV" en La Ciencia Tomista. 1957, nº 84, pp. 95-116.

CARABIAS TORRES, A. M. El Colegio Mayor de Cuenca en el siglo XVI: Estudio institucional. Salamanca: Universidad de Salamanca, 1983.

CARABIAS TORRES, A. M. "Evolución histórica del Colegio Trilingüe de Salamanca: 1550-1812" en Stvdia Histórica. Historia Moderna. Salamanca, vol. I, no 3, pp. 143-168. (1983).

CARABIAS TORRES, A. M. Colegios Mayores: Centros de Poder. Los Colegios Mayores de Salamanca durante el siglo XVI. Salamanca: Universidad de Salamanca, 1986, 3 vols.

CARABIAS TORRES, A. M. "El poder de las letras. Colegios Mayores salmantinos en la administración americana". En: Primeras Jornadas sobre la presencia universitaria española en la América de los Austrias (1535-1700). Alcalá, 1987, pp. 2-28.

CARABIAS TORRES, A. M. "Notas sobre las relaciones entre el Estado y la Universidad en la España moderna" en Stvdia Histórica. Historia Moderna. Homenaje al Prof. M. Fernández Álvarez. Salamanca, vol. III, 1989, pp. 707-721.

FERNÁNDEZ ÁLVAREZ, M. "La reforma universitaria de 1512" en Stvdia Histórica. Historia Moderna. Salamanca: Eds. Universidad de Salamanca, vol. II, nº 3, 1984, pp. 21-46.

FERNÁNDEZ ÁLVAREZ, Manuel "Los Libros de Claustros de la Universidad de Salamanca en la época de Francisco de Vitoria". En: Salamanca y su proyección en el mundo. Estudios históricos en honor de D. Florencio Marcos. Salamanca, 1992, pp. 137-152

FERNÁNDEZ ÁlVAREZ, M.; ROBLES CARCEDO, L.; RODRÍGUEZ SAN PEDRO, L. E. (Eds.) La Universidad de Salamanca. Salamanca: Ediciones Universidad de Salamanca, 1990, 3 vols.

FERNÁNDEZ UGARTE, M. "Estatutos de la Universidad de Salamanca: la Reforma de 1550-1551" en Stvdia Historica. Historia Moderna, vol. VII, 1989, pp. 687-705.

FUERTES, J.L. Estatutos de la Universidad de Salamanca, 1529. Mandato de Pérez de Oliva, Rector. Salamanca: Universidad de salamanca, 1984.

GARCÍA BOIZA, A. La intervención de los estudiantes en la Universidad de Salamanca en el s. XVI. Salamanca, 1933.

GARCíA ORO, J. "Las reformas pretridentinas en los Colegios Religiosos de Salamanca" en Stvdia historico-ecclesiastica. Festgabe für Prof. Luchesius G. Spätling O.F.M. herausggeben von Isaac Vázque O.F.M.. Roma, 1977, pp. 613-656.

GARCÍA ORO, J.; y PORTELA SILVA, M. ${ }^{a}$ J. Felipe Il y la Universidad de Salamanca. Las visitas del Consejo Real. Santiago de Compostela: Imprenta Aldecoa, 1998.

GONZÁLEZ DE LA CALLE, P.U.; HUARTE Y ECHENIQUE, A. "Constituciones de la Universidad de Salamanca (1422). Edición paleográfica con prólogo y notas." en Revista de Archivos, Bibliotecas y Museos. Madrid, n 46, 1925, pp. 217-228, 345-359, y 402-419; n47, 1926, pp. 348-371, y 467-501. 
GONZÁLEZ DE LA CALLE, P.U. y HUARTE Y ECHENICHE, A. "Constituciones de la Universidad de Salamanca, 1422. Edición paleográfica" en Revista de Archivos, Bibliotecas y Museos, III-XXIX, 1935, pp. 217, 345, 402. 1935; 1936, III-XXX, pp. 348.

HERNÁNDEZ MONTES, B. "El Colegio de la Compañía y la Universidad de Salamanca en el siglo XVI. Desde los orígenes hasta la incorporación a la Universidad" en Stvdia Histórica. Historia Moderna. Homenaje al Prof. M. Fernández Álvarez. Salamanca, vol. III, 1989, pp. 723-744.

MÉNDEZ SANZ, F. La Universidad Salmantina de la llustración, 1750-1800: Hacienda y Reforma. Salamanca: Universidad de Salamanca, 1988.

PESET, M. "La enseñanza del Derecho y la legislación sobre Universidades durante el reinado de Fernando VII (1808-1833)" en Anuario de Historia del Derecho español, 1968, XXXVIII, pp. 220-375.

PESET, M. "Universidad y enseñanza del Derecho durante las regencias de Isabel II (1833-1843)" en Anuario de Historia del Derecho español, 1969, XXXIX, pp. 481-544.

PESET, M. "El Plan Pidal de 1845 y le enseñanza en las Facultades de Derecho" en Anuario de Historia del Derecho español, 1970, XL, pp. 613-651.

PESET, M. "Modelos y estatutos de las universidades españolas y portuguesas (siglos XIII-XVIII)". En: Dall'Università degli studenti all'Università degli studi, a cura di Andrea Romano. Messina: Presso l'Accademia di Scienze Giuridiche, 1991, pp. 65-105.

PESET REIG, J. L. "La organización de las universidades españolas en la edad moderna". En: ROMANO, Andrea (Ed.) Studi e Diritto nell'area in etá moderna, Rubbettino, 1993, pp.73-122.

PESET REIG, M.; PESET REIG, J. L. El reformismo de Carlos IIl y la Universidad de Salamanca. Plan general de estudios dirigido a la Universidad de Salamanca por el Real y Supremo Consejo de Castilla en 1771. Salamanca, 1969.

PESET REIG, M.; PESET REIG, J.L. La Universidad española. Siglos XVIII y XIX. Despotismo ilustrado y revolución liberal. Madrid, 1974.

PESET REIG, M.; PESET REIG, J. L. "Poder y reforma de la Universidad de Salamanca en tiempos de Carlos III". En: GONZÁLEZ. E. (Ed.) Historia y universidad. Homenaje a Mariano Lorenzo Luna. México: U.N.A.M., 1996, pp. 457-480.

POLO RODRÍGUEZ, J. L. "La autoridad rectoral y sus consejeros en la Universidad de Salamanca: 1700-1759" en Salamanca. Revista Provincial de Estudios. Salamanca, n² 29-30, 1992, pp. 129-200.

POLO RODRÍGUEZ, J. L. "Veintinueve apercibimientos del juez de Estudio de la Universidad de Salamanca (1736-1739)" en Cuadernos de historia moderna. Madrid: Editorial Complutense, nº 15, 1994, pp.143-167.

POLO RODRÍGUEZ, J.L. La Universidad Salmantina del Antiguo Régimen (1700-1750). Salamanca: Universidad de Salamanca, 1995

POLO RODRÍGUEZ, J. L. "Reformas en la Universidad de Salamanca de los primeros Borbones (1700-1759)" en Espacio Tiempo y Forma. Madrid: U.N.E.D., serie IV, nº 7, 1995, pp. 145-173.

POLO RODRÍGUEZ, J. L. "Poderes representativos en la Universidad de Salamanca del siglo XVIII: rector y consiliarios". En: Historia y Universidad. Homenaje a Lorenzo Mario Luna. México: U.N.A.M., 1996, pp. 481-517.

POLO RODRÍGUEZ, J.L. "La Universidad salmantina del Setecientos. Pervivencias estructurales del pasado". En: Actas del V Congreso Internacional sobre Historia de las Universidades Hispánicas. Valladolid: Junta de Castilla y León, Universidad de Salamanca, 1998

RODRÍGUEZ CRUZ, A. El oficio de Rector en la Universidad de Salamanca y en las Universidades Hispanoamericanas. Desde sus orígenes hasta principios del siglo XIX. Salamanca: Universidad de Salamanca, 1979.

RODRíGUEZ CRUZ, A. Historia de la Universidad de Salamanca. Madrid. Fundación Ramón Areces. 1990.

RODRÍGUEZ CRUZ, A. "Análisis comparativo de las constituciones universitarias de Salamanca con las hispanoamericanas" en Estudios de historia social y económica de América. Alcalá de Henarés, nº 13, 1996, pp. 583-591.

RODRÍGUEZ-SAN PEDRO BEZARES, L.E. La Universidad Salmantina del Barroco, período 1598-1625. Tesis doctoral. Salamanca: Universidad de Salamanca y Caja de Ahorros de Salamanca, 1986, 3 vols.

RODRÍGUEZ-SAN PEDRO BEZARES, L.E. (Estudio y ed.) Estatutos hechos por la Universidad de Salamanca (1625). Salamanca: eds. Universidad de Salamanca, 1990.

RODRÍGUEZ-SAN PEDRO BEZARES, L.E. "La Universidad de Salamanca: Evolución y declive de un modelo clásico" en Stvdia histórica. Historia Moderna. Salamanca: eds. Universidad de Salamanca, n IX, 1991, pp. 9-21. 
RODRÍGUEZ-SAN PEDRO BEZARES, L.E. "La evolución del corpus legislativo de la Universidad de Salamanca (ss. XVXVIII). Estado de la cuestión" en Estudios de historia social y económica de América. Alcalá de Henares, nº 13, 1996, pp.573582.

RODRÍGUEZ-SAN PEDRO BEZARES, L.E. "Poderes y corpus normativo en la Universidad de Salamanca (siglos XV-XVIII)" en Cuadernos del Instituto Antonio de Nebrija de Estudios sobre la Universidad, 1, 1998, pp. 289-308.

RODRÍGUEZ-SAN PEDRO BEZARES, L.E. (coord.). Historia de la Universidad de Salamanca. Salamanca: Universidad de Salamanca, 2002-2009. (6 vols.)

RODRÍGUEZ-SAN PEDRO BEZARES, L.E. y POLO RODRÍGUEZ, J.L. (eds.), Fuentes archivos y bibliotecas para una historia de las Universidades Hispánicas. Miscelánea Alfonso IX, 2014, Salamanca, Ediciones Universidad de Salamanca, 2015,432 pp.

SALA BALUST, L. Catálogo de fuentes para la historia de los antiguos Colegios seculares de Salamanca. Madrid-Barcelona, 1954

SALA BALUST, L. "Las primeras Constituciones del Colegio de San Bartolomé de Salamanca, copia de los primeros Estatutos del Colegio de San Clemente de Bolonia". En: Miscelánea Antonio Pérez Goyena. Estudios Eclesiásticos. n 35, pp. 253-263. (1960).

SALA BALUST, L. Constituciones, Estatutos y Ceremonias de los Antiguos Colegios Seculares de la Universidad de Salamanca. Madrid: Edición Crítica, 4 vols. (1962-66).

SÁNCHEZ SÁNCHEZ, D. La Universidad de Salamanca a través de sus claustros. Estructura jerárquica y académica (15551575). Tesis doctoral inédita. Salamanca, 4 vols .(1980).

SÁNCHEZ SÁNCHEZ, D. "El oficio de maestrescuela en la Universidad de Salamanca". En: Salamanca y su proyección en el mundo. Estudios históricos en honor de D. Florencio Marcos. Salamanca: Gráficas Ortega, 1992, pp. 61-80.

SANTANDER RODRÍGUEZ, T. "Fuentes para una historia de la Universidad de Salamanca". En: La Universidad de Salamanca. Salamanca: Universidad de Salamanca, vol. II, 1990, pp. 297-312.

SAUGNIEUX, J. La llustración cristiana española. Escritos de Antonio Tavira (1737-1807). Salamanca, 1986.

VALERO GARCÍA, P., "Un aspecto del rectorado de Fernán Pérez de Oliva: pretendidos Estatutos de la Universidad de Salamanca bajo su mandato" en Stvdia Histórica. Historia Moderna. Salamanca, vol. IV, 1986, pp. 51-74. (1986).

VIVAS MORENO, A. Fondos documentales del Archivo Universitario de salamanca. La Colección de Papeles Varios: análisis descriptivo, tesauro y gestión documental automatizada. Tesis doctoral. Salamanca, 1998.

VIVAS MORENO, A. El Archivo Histórico de la Universidad de Salamanca. Gijón: Trea, 2003.

VIVAS MORENO, A "El Archivo Universitario de Salamanca: historia y procedencias documentales" en Revista de Información y Documentación. Madrid: Universidad Complutense, nº 22, 1999, pp. 117-148.

VIVAS MORENO, A. "Series documentales para el estudio de la trayectoria estudiantil y docente en las universidades de Antiguo Régimen. El ejemplo del Archivo Histórico de la Universidad de Salamanca" en Salamanca. Revista de Estudios. Salamanca: Diputación Provincial de Salamanca, 2000, nº 44, pp. 271-297.

VIVAS MORENO, A. "La documentación hacendística en los archivos históricos universitarios: el modelo de Salamanca" en Investigación Biblioteconómica, vol. 14, nº 29, 2000, pp. 43-67. 


\section{Datos de los autores}

\section{Agustín Vivas Moreno}

Doctor en Documentación con un trabajo sobre el Archivo de la Universidad de Salamanca. En la actualidad es Profesor Titular de Universidad en la Facultad de Biblioteconomía y Documentación de la Universidad de Extremadura. En sus publicaciones se ha ocupado, entre otras cuestiones, de diferentes aspectos concernientes a la clasificación archivística, la historia cultural de los archivos, la historia de la lectura, o la documentación histórica universitaria. Por otro lado, ha atendido a la documentación aplicada al trabajo histórico, resorte de los denominados Sistemas de Información Histórica, donde el estudio del documento se constituye como objeto de análisis común a Archivística e Historia. Es Decano de la Facultad de Biblioteconomía y Documentación de la Universidad de Extremadura.

aguvivas@unex.es

Recibido - Received: 2016-07-05

Aceptado - Accepted: 2017-03-18

\section{$(\mathrm{cc})$ EY}

This work is licensed under a Creative Commons Attribution 4.0

United States License.

\section{UILIS D-Sorke}

This journal is published by the University Library System of the University of Pittsburgh as part of its D-Scribe Digital Publishing Program and is cosponsored by the University of Pittsburgh Press. 